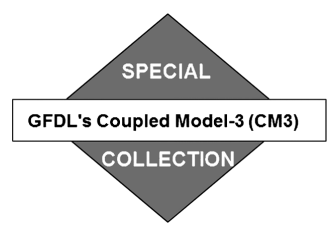

\title{
The GFDL CM3 Coupled Climate Model: Characteristics of the Ocean and Sea Ice Simulations
}

\author{
StePHEN M. Griffies,* Michael Winton,* LeO J. DONNER,* LARRy W. Horowitz,* \\ StePhanie M. Downes, ${ }^{+}$Riccardo FARneti, ${ }^{*}$ AnAND GNANADESIKAN, ${ }^{*}$ William J. Hurlin, ${ }^{*}$ \\ Hyun-Chul LeE, ${ }^{@}$ Zhi LiAng, ${ }^{@}$ JAIME B. PAlter, ${ }^{+}$Bonita L. SAMuels, ${ }^{*}$ \\ ANDREW T. WitTENBERG, ${ }^{*}$ BRUCE L. WyMAN, ${ }^{*}$ JiANJUN Yin, ${ }^{\&}$ AND NiKI ZADEH ${ }^{@}$ \\ * NOAA/Geophysical Fluid Dynamics Laboratory, Princeton, New Jersey \\ + Atmospheric and Oceanic Sciences Program, Princeton University, Princeton, New Jersey \\ \# Earth System Physics Section, ICTP, Trieste, Italy \\ ${ }^{\circledR}$ High Performance Technologies, Inc., and Geophysical Fluid Dynamics Laboratory, Princeton, New Jersey \\ \& Department of Geosciences, The University of Arizona, Tucson, Arizona
}

(Manuscript received 2 August 2010, in final form 7 March 2011)

\begin{abstract}
This paper documents time mean simulation characteristics from the ocean and sea ice components in a new coupled climate model developed at the NOAA Geophysical Fluid Dynamics Laboratory (GFDL). The GFDL Climate Model version 3 (CM3) is formulated with effectively the same ocean and sea ice components as the earlier CM2.1 yet with extensive developments made to the atmosphere and land model components. Both CM2.1 and CM3 show stable mean climate indices, such as large-scale circulation and sea surface temperatures (SSTs). There are notable improvements in the CM3 climate simulation relative to CM2.1, including a modified SST bias pattern and reduced biases in the Arctic sea ice cover. The authors anticipate SST differences between CM2.1 and CM3 in lower latitudes through analysis of the atmospheric fluxes at the ocean surface in corresponding Atmospheric Model Intercomparison Project (AMIP) simulations. In contrast, SST changes in the high latitudes are dominated by ocean and sea ice effects absent in AMIP simulations. The ocean interior simulation in CM3 is generally warmer than in CM2.1, which adversely impacts the interior biases.
\end{abstract}

\section{Introduction}

The purpose of this paper is to document elements of the ocean and sea ice simulations in a new coupled climate model developed at the Geophysical Fluid Dynamics Laboratory (GFDL). This paper is a companion to that of Donner et al. (2011), which focuses on the atmospheric formulation and simulation features of the climate model. In addition to being used to help address various hypothesis-driven scientific research questions, the GFDL Climate Model version 3 (CM3) will be one of the primary models from GFDL contributing to the Intergovernmental Panel on Climate Change (IPCC) Fifth Assessment Report (AR5).

Corresponding author address: Stephen M. Griffies, NOAA/ GFDL, 201 Forrestal Rd., Princeton, NJ 08542.

E-mail: stephen.griffies@noaa.gov
CM3 builds from the extensive experience garnered from the earlier GFDL Climate Model version 2.1 (CM2.1), documented by Delworth et al. (2006), Griffies et al. (2005), Gnanadesikan et al. (2006), Wittenberg et al. (2006), and Stouffer et al. (2006a). The development forward from CM2.1 took two paths. The first path emphasized the needs of earth system modeling in which interactive ocean biogeochemistry, land vegetation, and interactive carbon cycling are critical. This path used nearly the same atmospheric model as in CM2.1 and it led to two new earth system models that differ only by their ocean components. The second development path, leading to CM3, is the focus of the present paper, as well as Donner et al. (2011). For CM3 priorities included aerosol-cloud interactions, chemistry-climate interactions, and links between the troposphere and stratosphere. Updates to the land model were also incorporated. To help achieve a state-of-the-science climate model tool using the new atmospheric model, in time for the AR5, 
we chose to keep the ocean and sea ice components of CM3 effectively the same as in CM2.1. The presentation here focuses on salient aspects of the surface ocean climate in CM3 and an introduction to interior biases and volume transports.

\section{a. Experimental design and analysis period}

The coupled climate model experiments forming the main portion of this paper employ historical radiative forcing from the years 1860-2000. Model comparisons use the ensemble mean and time mean from a five-member ensemble of historical experiments in CM2.1 and CM3 over the years 1981-2000. Each ensemble member was initialized from a different point during the 1860 radiatively forced spinups for the two respective models, with CM2.1 ensemble members initialized 40 years apart and $\mathrm{CM} 3$ ensemble members initialized 50 years apart. For our purposes, the combined ensemble and time means allow for a robust signal to be revealed from among the natural variability present within individual ensemble members.

The analysis of historically forced simulations contrasts with the use of 1990 radiative forcing experiments by Delworth et al. (2006), Griffies et al. (2005), Gnanadesikan et al. (2006), and Wittenberg et al. (2006) used to document CM2.1. We chose to focus on historically forced simulations since they are, in principle, more amenable to direct comparisons to observed fields than 1990 or 1860 control simulations. Additionally, historical simulations represent a key element of the IPCC climate assessment. However, the historically forced simulations present nontrivial and unresolved difficulties related to model drift. We raise two points here in this regard.

There are insufficient 1860 ocean observations to directly initialize such "preindustrial" climate simulations. Hence, we initialize the ocean based on present conditions (Steele et al. 2001) and run the climate model with constant 1860 radiative forcing for multiple centuries. This approach is similar to that discussed in Stouffer et al. (2004). The aim is to reach a quasi equilibrium prior to the changing "historical" atmospheric forcing from years 1860-2000. A key difficulty with this procedure is that equilibrium in the deep ocean is reached only after one or two thousand years (Stouffer 2004). Computational costs precluded this length of simulation, thus compromising the degree of ocean climate equilibration. Additionally, during spinup of both CM3 and CM2.1, the two oceans absorb heat as they approach equilibrium, as a result of model biases. Hence, the global mean ocean temperature is increasing relative to the 1990 initial conditions, rather than decreasing. Such ocean warming drift is not uncommon for IPCC class climate models, as evidenced from the interior biases seen in the ensemble of historically forced climate models in Fig. 8.9 of Randall et al. (2007) (we show such biases for CM2.1 and CM3 in Fig. 14 discussed in section 3a).

CM3 has a larger net input of heat to the ocean, thus causing it to warm faster than CM2.1. In particular, for an Atmospheric Model Intercomparison Project (AMIP) simulation of the two atmospheric model components from CM2.1 and CM3, known as AM2 and AM3, respectively, the top-of-the-atmosphere radiative imbalance for model years $1981-1998$ is roughly $0.4 \mathrm{~W} \mathrm{~m}^{-2}$ in AM2, whereas it equals $0.6 \mathrm{~W} \mathrm{~m}^{-2}$ for AM3. ${ }^{1}$ This radiative imbalance roughly corresponds to that from observational estimates of upper-ocean heat uptake by (Lyman et al. 2010), who suggest a net ocean heating of $0.5-0.75 \mathrm{~W} \mathrm{~m}^{-2}$. Besides aiming to remain within bounds of observational estimates, atmospheric radiative tuning aims to reduce overall surface climate biases (e.g., sea surface temperature). However, biases are confounded by long-term climate drifts, which, unfortunately, are unknown at the time of atmospheric development.

Heat imbalances in the AMIP simulations are indicative of the enhanced warming occurring in $\mathrm{CM} 3$ relative to $\mathrm{CM} 2.1$, yet the imbalances are modified upon coupling. For example, we illustrate how the heating differences manifest in coupled climate simulations in which the ocean components are initialized from the same conditions and the climate models are forced with 1990 radiative conditions. Time series of global mean ocean temperature in Fig. 1 show that CM3 warms more rapidly than CM2.1, with roughly $0.1 \mathrm{~W} \mathrm{~m}^{-2}$ more heat present in the CM3 atmosphere than CM2.1.

Given that CM3 warms more rapidly than CM2.1, a related difficulty with a comparison of CM2.1 and CM3 historical experiments concerns the differing time used for the respective spinup simulations. CM2.1 was run for about 300 years prior to initializing the historical simulations. As stated earlier, this is a rather short period that does not allow the model to reach its equilibrium state. For CM3, after spinning up with 1860 forcing for roughly 500 years with the same solar constant used for the CM2.1 simulations, we switched to a smaller constant (reducing the net solar fluxes reaching the earth by about $1 \mathrm{~W} \mathrm{~m}^{-2}$ ), as recommended for the AR5 assessment based on new solar irradiance measurements (Kopp et al. 2005). CM3 was then run for roughly 300 years with the new solar constant prior to initializing the ensemble of historical simulations. The net effect is that $\mathrm{CM} 3$, having run for 800 years during the spinup phase, is closer to its

\footnotetext{
${ }^{1}$ AMIP simulations refer to atmosphere-land simulations with fixed sea surface temperature, run according to the protocol of the Atmospheric Model Intercomparison Project (Gates 1993).
} 


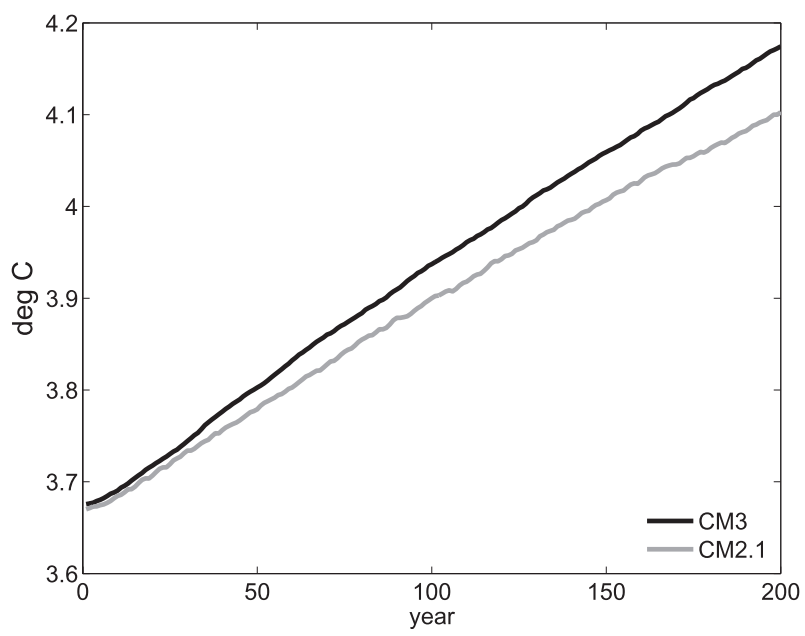

FIG. 1. Time series of the global mean ocean potential temperature for CM2.1 and CM3 when run with 1990 radiative forcing. The net heating of the CM3 ocean corresponds to roughly $0.85 \mathrm{~W} \mathrm{~m}^{-2}$ (using the total earth surface area) over this period, whereas the CM2.1 ocean heating is roughly $0.75 \mathrm{~W} \mathrm{~m}^{-2}$. Note that ocean warming is commonly seen in climate models, even for preindustrial simulations, as shown by Fig. 2a of Lucarini and Ragone (2011).

equilibrium state than CM2.1 upon initializing the historical simulations. In turn, CM3 is significantly warmer in the global ocean mean at the start of its historical simulations, by roughly $1^{\circ} \mathrm{C}$.

In summary, our aim to compare the historical simulations of CM3 to CM2.1 must be considered with the above caveats. Consequently, we focus on features, especially in the surface ocean, that appear robust across the historical simulations. For the ocean interior, it is especially important to retain an appreciation of the differences in spinup when assessing model differences. Though the interior bias patterns differ in scale, they exhibit a strong correlation since the ocean components are nearly the same.

\section{b. Content of this paper}

Section 2 begins the paper with a discussion of salient properties of the ocean surface, including sea surface temperature, salinity, sea ice, and sea level. Section 3 then considers some of the water mass biases seen in the ocean interior, with the dominant bias arising from the heat in CM3 associated with initialization from the warmer spinup simulation. We then present certain features of the volume transport for both the global and Atlantic overturning circulation, as well as the horizontal transport through selected straits and throughflows. Section 4 finishes the main text with discussion and conclusions. Details of the ocean and sea ice model components are provided in the appendix.

\section{Ocean surface properties}

The purpose of this section is to examine certain surface ocean properties, including sea ice, with comparisons made between CM2.1 and CM3 from years 1981-2000 in the historically forced simulations. In describing differences between the models, we identify salient changes in the atmospheric fluxes, as revealed by AMIP simulations of AM2-GFDL Land Model version 2 (LM2) (GFDL GAMDT 2004 and AM3-LM3 (Donner et al. 2011), which are the atmosphere and land model components from CM2.1 and CM3, respectively.

\section{a. Sea surface temperature}

Sea surface temperature (SST) is directly affected by coupling to the atmosphere, sea ice, and river runoff from land. SST bias patterns form a primary metric used to judge the integrity of a climate simulation, with biases impacted by the suite of ocean surface buoyancy and momentum fluxes, as well as the realism of surface ocean flow. Figure 2 shows maps of the SST biases for CM2.1 and CM3 relative to the climatology of Reynolds et al. (2002). The global mean bias is roughly the same for both models, and some large-scale features are common. However, there are some notable changes, as evidenced by the root-mean-square biases as categorized by latitude bands. In general, CM3 has a somewhat smaller rms error in the high latitudes, whereas CM2.1 has a smaller rms error in the tropics. In the remainder of this subsection, we discuss possible physical mechanisms impacting these biases and connect regional bias patterns to these physical mechanisms.

\section{1) Correlating SST CHANGes With Surface FLUX CHANGES}

Ocean surface temperatures differ between the coupled models due to either changes in surface boundary fluxes or through differences in oceanic heat transport from advection and subgrid-scale processes. For example, as discussed in Donner et al. (2011), changes made to the CM3 atmosphere result in a complex pattern of changes in radiative fluxes relative to CM2.1. In particular, Fig. 3 shows the annual mean absorbed shortwave radiation at the top of the atmosphere for the atmospheric models AM2 and AM3 and the coupled climate models CM2.1 and CM3. A dominant change between the models is the reduced heating bias in the Southern Ocean for AM3 and $\mathrm{CM} 3$. We also note a slightly warmer North Pacific in CM3. Further details of these radiative changes are noted in Donner et al. (2011). Though details will be modified owing to scattering by aerosols and clouds, these changes in the top-of-the-atmosphere radiative fluxes reflect on the surface ocean fluxes. 
CM2.1 minus obs SST
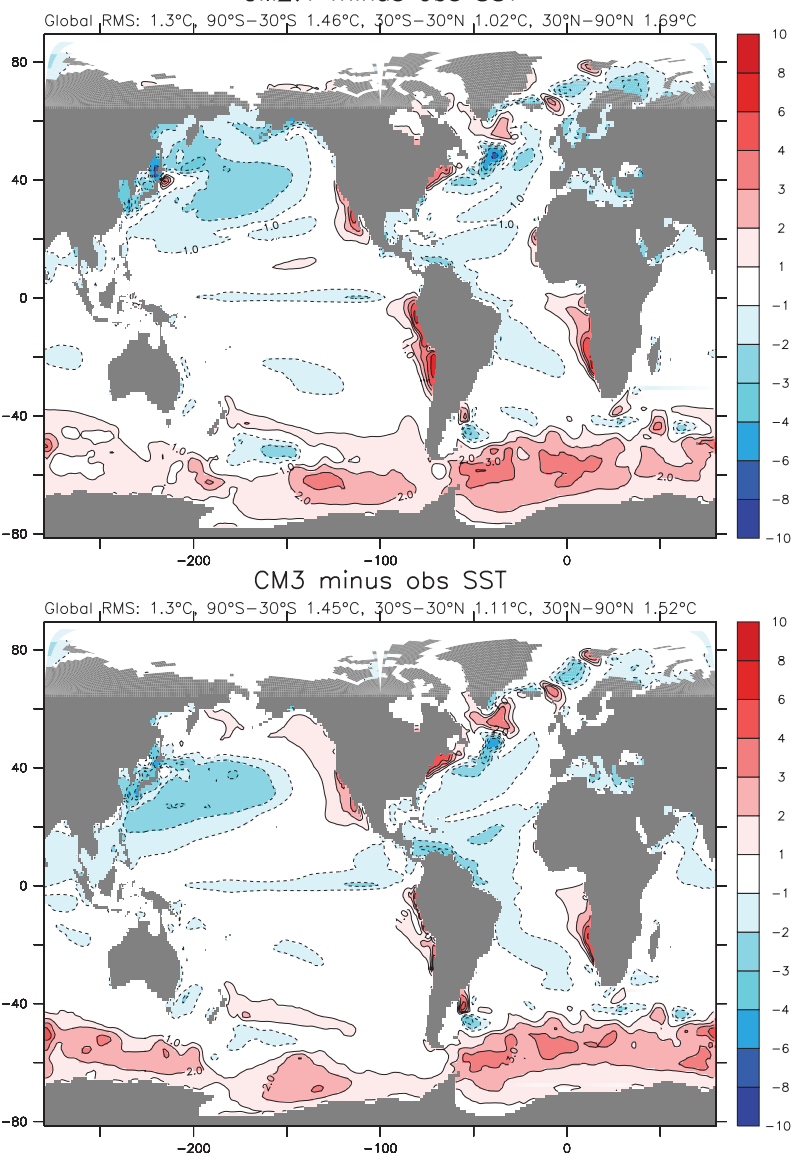

FIG. 2. Maps of SST from CM2.1 and CM3, minus the observational analysis of Reynolds et al. (2002). The model results are computed as ensemble means from the historically forced experiments over simulation years 1981-2000. Biases are in degrees Celsius. White regions indicate biases whose absolute values are less than one degree. Global and regional rms errors are listed and are summarized as (top) $\mathrm{CM} 2.1$ : Global $=1.3^{\circ} \mathrm{C}, 90^{\circ}-30^{\circ} \mathrm{S}=$ $1.46^{\circ} \mathrm{C}, 30^{\circ} \mathrm{S}-30^{\circ} \mathrm{N}=1.02^{\circ} \mathrm{C}, 30^{\circ}-90^{\circ} \mathrm{N}=1.69^{\circ} \mathrm{C}$ and (bottom) $\mathrm{CM}$ 3: Global $=1.3^{\circ} \mathrm{C}, 90^{\circ}-30^{\circ} \mathrm{S}=1.45^{\circ} \mathrm{C}, 30^{\circ} \mathrm{S}-30^{\circ} \mathrm{N}=1.11^{\circ} \mathrm{C}, 30^{\circ}-$ $90^{\circ} \mathrm{N}=1.52^{\circ} \mathrm{C}$.

To help attribute changes in SST, we distinguish regions where changes in surface ocean heat fluxes (turbulent and radiative) are important by examining differences in the diagnosed air-sea heat fluxes in AMIP simulations using fixed SST boundary conditions (Fig. 4a). If the ocean were able to maintain these surface fluxes, the sea surface heat balance would allow the observed SSTs to persist. If the ocean component does not supply the expected flux under the atmosphere's forcing, the SST will drift.

The heat flux changes seen between the AM2 and AM3 atmospheric models correlate relatively well with the difference in SST seen in the climate models CM2.1 and CM3 for the regions between $40^{\circ} \mathrm{S}$ and $30^{\circ} \mathrm{N}$, with a correlation coefficient of 0.59 . The heat flux changes correspondingly have some skill in predicting the SST changes between $30^{\circ}$ and $65^{\circ} \mathrm{N}$. Poleward of $65^{\circ} \mathrm{N}$, the correlations are much lower and in the Southern Hemisphere they are essentially zero. This result suggests that much of the SST difference in the low latitudes is controlled by the atmosphere, whereas in high latitudes, the changes in oceanic heat transport and sea ice properties dominate. Examining the correlation between changes in SST in the coupled models and the change in the coupled model net surface flux (Fig. 4b) reveals that now the tropics are poorly correlated with the changes in the net flux. This result is consistent with the SSTs adjusting to changes in atmospheric forcing locally in the lower latitudes, so as to leave a small residual and hence a small correlation. By contrast, in high latitudes the SST changes are anticorrelated with changes in air-sea heat flux, suggesting that the changes are forced by oceanic heat transport and are damped by the atmosphere.

\section{2) Poleward heat transport}

The ocean heat transport implied by surface fluxes in an atmospheric simulation with observed SSTs is useful for understanding the potential for climate model drift (Fig. 5). Additionally, the atmosphere implied transports can be compared to observational and reanalysis estimates to assess their fidelity. Hence, it is useful to illustrate the heat transports for general purposes of model documentation and to help interpret changes in the SST biases between the climate models.

In the Atlantic, Fig. 5 indicates that both atmospheric models show somewhat weak implied oceanic heat transports as compared to the in situ measurements analyzed by Ganachaud and Wunsch (2003), though the models are within the range determined by the two reanalysis products used by Trenberth and Caron (2001). When coupled, the transport in both climate models further decreases in the lower latitudes, with poleward ocean heat transport in CM3 generally less than CM2.1. For the higher northern latitudes (north of $40^{\circ} \mathrm{N}$ ) both models are more consistent with one another and slightly greater than the reanalysis implied transports, but consistent with in situ measurements. The warming of the SST in CM3 relative to CM2.1 is predominantly through the atmosphere in this region (see Fig. 4).

For the Southern Ocean there is a notable equatorward implied global heat transport in AM2-LM2 within the latitude band centered just south of $40^{\circ} \mathrm{S}$. This transport arises from the positive bias (directed into the ocean) in the Southern Ocean surface heat flux in AM2. This bias, in turn, is associated with a positive bias in absorbed shortwave radiation shown in Fig. 3. As discussed by Delworth et al. (2006), radiative biases can 


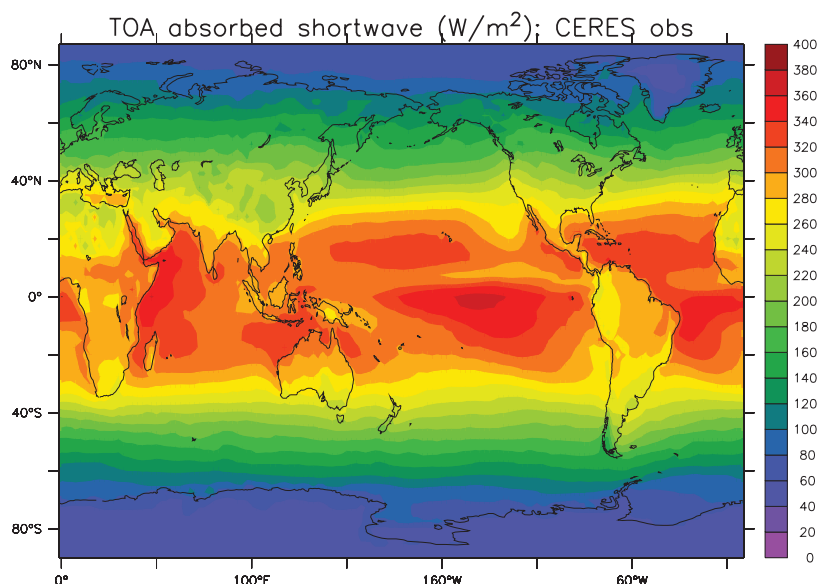

TOA absorbed shortwave $\left(\mathrm{W} / \mathrm{m}^{2}\right)$ : AM2 minus obs

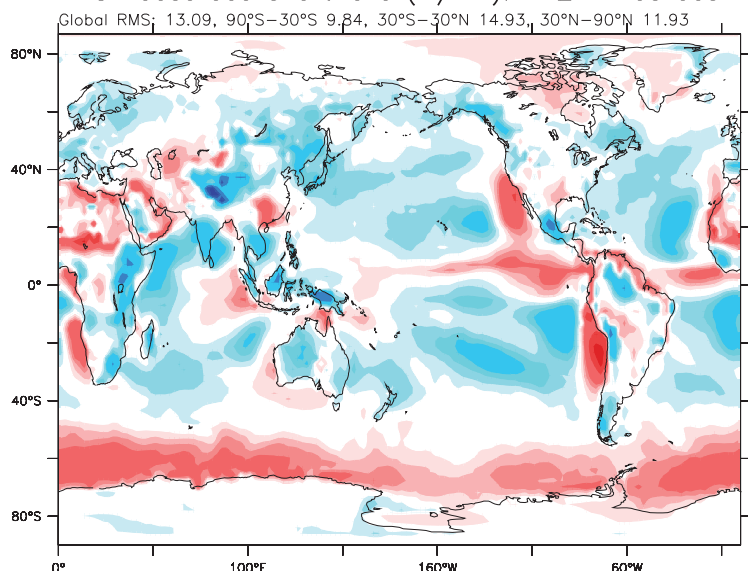

TOA absorbed shortwave $\left(\mathrm{W}^{160^{\circ} \mathrm{W}} \mathrm{m}^{2}\right)$ : CM2.1 minus obs
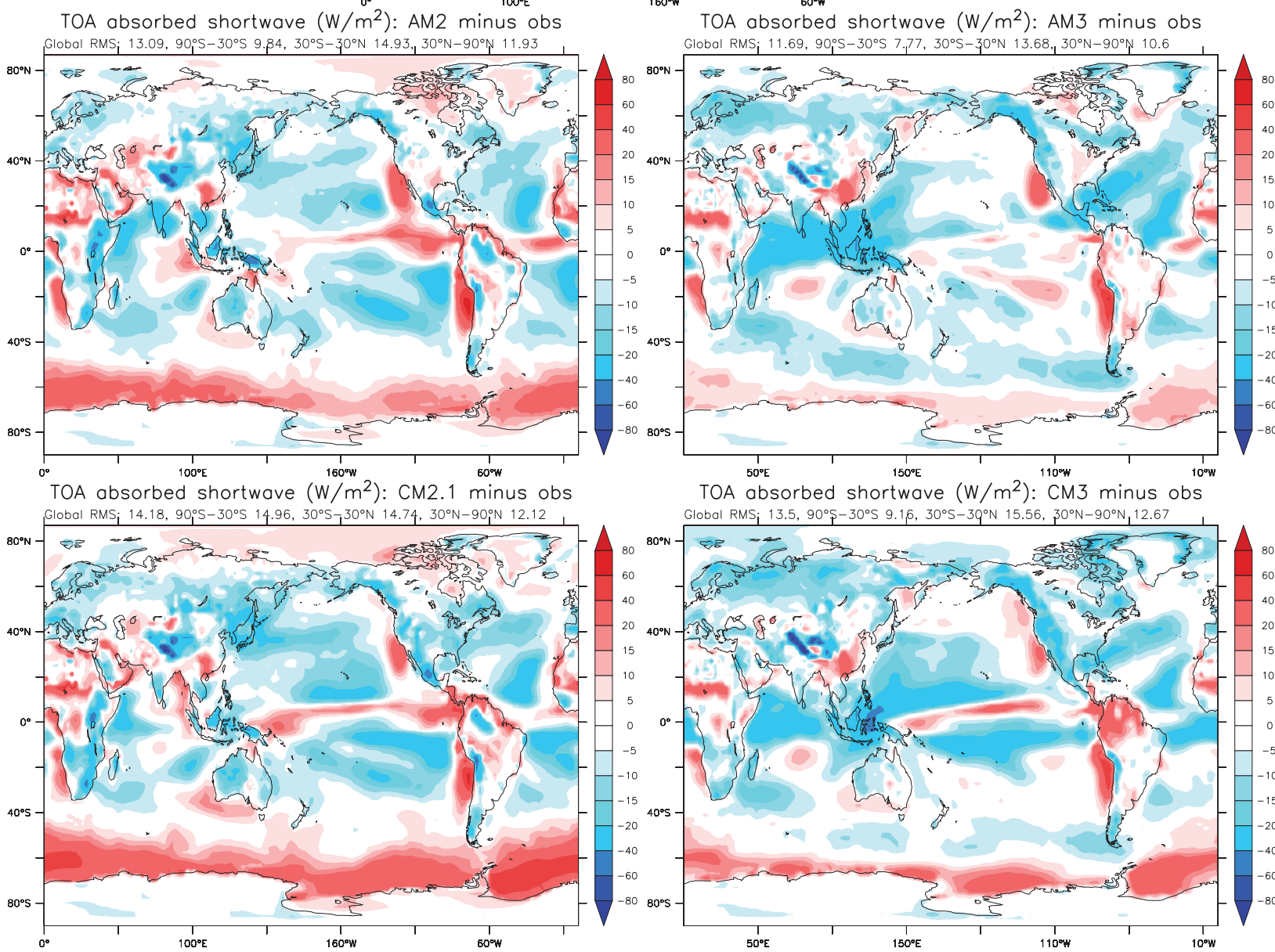

(W/ming

Global RMS; $11.69,90^{\circ} \mathrm{S}-30^{\circ} \mathrm{S} 7.77,30^{\circ} \mathrm{S}-30^{\circ} \mathrm{N} 13.68,30^{\circ} \mathrm{N}-90^{\circ} \mathrm{N} 10.6$

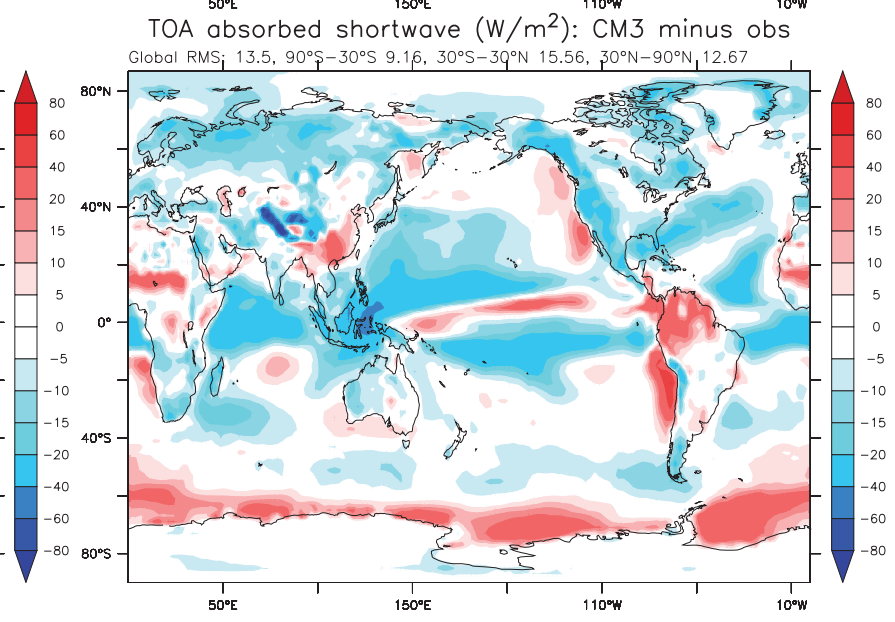

FIG. 3. Observed and simulated annual-mean absorbed shortwave radiation at the top-of-the-atmosphere. The observed values are taken from the Clouds and the Earth's Radiant Energy System Energy Balanced and Filled (CERES-EBAF) product (Loeb et al. 2009) based on observed years 2000-05. Errors are computed as model minus observations. Shown are model results from the AMIP simulations with AM2-LM2 and AM3-LM3 (climatology based on years 1983-98), as well as the coupled model simulations CM2.1 and CM3 (ensemble mean for years 1981-2000). The global and regional rms errors are listed at the top of each panel and are summarized as follows, AM2: Global $=13.09 \mathrm{~W} \mathrm{~m}^{-2}, 90^{\circ}-30^{\circ} \mathrm{S}=9.84 \mathrm{~W} \mathrm{~m}^{-2}, 30^{\circ} \mathrm{S}-30^{\circ} \mathrm{N}=14.93 \mathrm{~W} \mathrm{~m}^{-2}, 30^{\circ}-90^{\circ} \mathrm{N}=11.93 \mathrm{~W} \mathrm{~m}{ }^{-2}$; $\mathrm{AM} 3$ : Global $=$ $11.69 \mathrm{~W} \mathrm{~m}^{-2}, 90^{\circ}-30^{\circ} \mathrm{S}=7.77 \mathrm{~W} \mathrm{~m}^{-2}, 30^{\circ} \mathrm{S}-30^{\circ} \mathrm{N}=13.68 \mathrm{~W} \mathrm{~m}^{-2}, 30^{\circ}-90^{\circ} \mathrm{N}=10.6 \mathrm{~W} \mathrm{~m}^{-2} ; \mathrm{CM} 2.1$ : Global $=14.18 \mathrm{~W} \mathrm{~m}^{-2}, 90^{\circ}-30^{\circ} \mathrm{S}=$ $14.96 \mathrm{~W} \mathrm{~m}^{-2}, 30^{\circ} \mathrm{S}-30^{\circ} \mathrm{N}=14.74 \mathrm{~W} \mathrm{~m}^{-2}, 30^{\circ}-90^{\circ} \mathrm{N}=12.12 \mathrm{~W} \mathrm{~m}^{-2}$; and CM3: Global $=13.50 \mathrm{~W} \mathrm{~m}^{-2}, 90^{\circ}-30^{\circ} \mathrm{S}=9.16 \mathrm{~W} \mathrm{~m}^{-2}$, $30^{\circ} \mathrm{S}-30^{\circ} \mathrm{N}=15.56 \mathrm{~W} \mathrm{~m}^{-2}, 30^{\circ}-90^{\circ} \mathrm{N}=12.67 \mathrm{~W} \mathrm{~m}^{-2}$. Note the pronounced reduction in shortwave bias in the Southern Ocean for AM3, as well as the slightly warmer North Pacific. Individual ensemble members from the climate models differ by no more than $\sim 5-10 \mathrm{~W} \mathrm{~m}^{-2}$. 
(a) $\mathrm{CM} 3-\mathrm{CM} 2.1, \triangle \mathrm{SST}$ (deg $\mathrm{K}$, color), AM3-AM2 $\triangle \mathrm{Net} \mathrm{SFC}\left(\mathrm{W} / \mathrm{m}^{2}\right.$, contour)

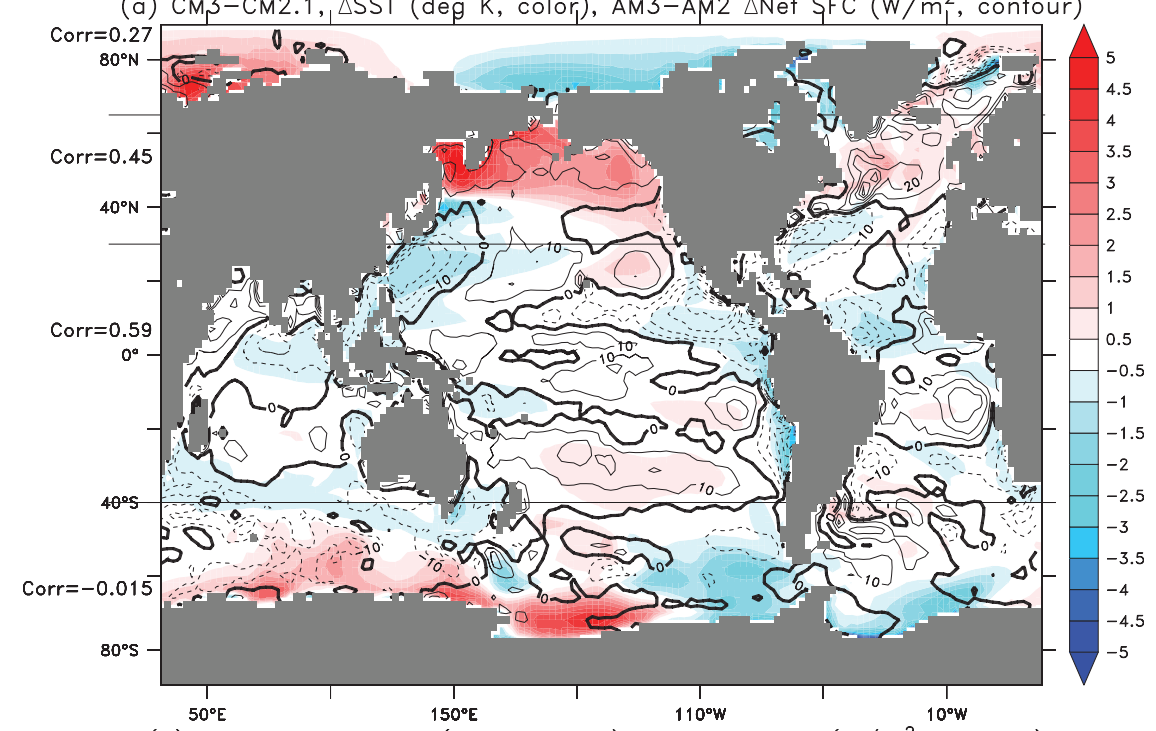

(b) CM3-CM2.1, $\triangle$ SST (deg K, color), $\triangle$ Net Sfc Flux $\left(\mathrm{W} / \mathrm{m}^{2}\right.$, contour)

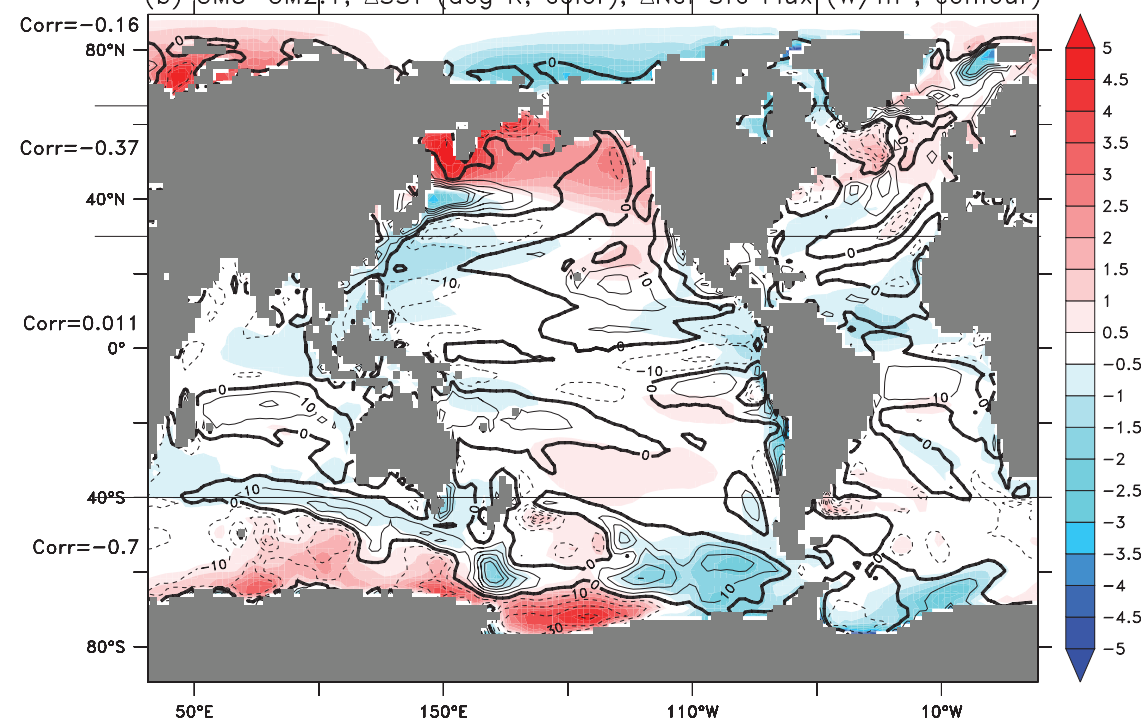

FIG. 4. Difference in SSTs for CM3 minus CM2.1 (color) computed from the ensemble means for the two climate models over years 1981-2000. Contours show the difference in surface ocean heat fluxes from the (top) AMIP simulations and (bottom) fully coupled climate simulations, where heat fluxes include shortwave, longwave, sensible, and latent heat impacting the surface ocean (sign chosen so that a positive flux enters the ocean). The spatial correlations between the SST changes and the surface heat flux changes are noted on the left ordinate. The spatial correlations are computed separately over the bands south of $40^{\circ} \mathrm{S}$, from $40^{\circ} \mathrm{S}$ to $30^{\circ} \mathrm{N}$, from $30^{\circ}$ to $65^{\circ} \mathrm{N}$, and poleward of $65^{\circ} \mathrm{N}$. Note that the fluxes shown here are taken from atmospheric model output. Since the atmospheric model has a coarser resolution than the ocean model, the land-sea mask is coarsened relative to other maps shown on the ocean grid (e.g., SSTs in Fig. 2).

amplify upon coupling due to cloud feedbacks, as seen in both the CM2.1 and CM3 radiative biases in the Southern Ocean. Figure 3 shows that AM3 has a greatly reduced bias in net absorbed shortwave within the Southern Ocean. Reducing this bias produces a slightly poleward implied heat transport within this latitude band.
In the Indo-Pacific, both atmospheric models imply less heat export from the tropics than the reanalysis products (Fig. 5). In the North Pacific, the lower implied transport in AM3-LM3 relative to AM2-LM2 is consistent with the smaller cold bias in CM3 as the atmosphere extracts less heat from this region (Fig. 5). The change in implied 

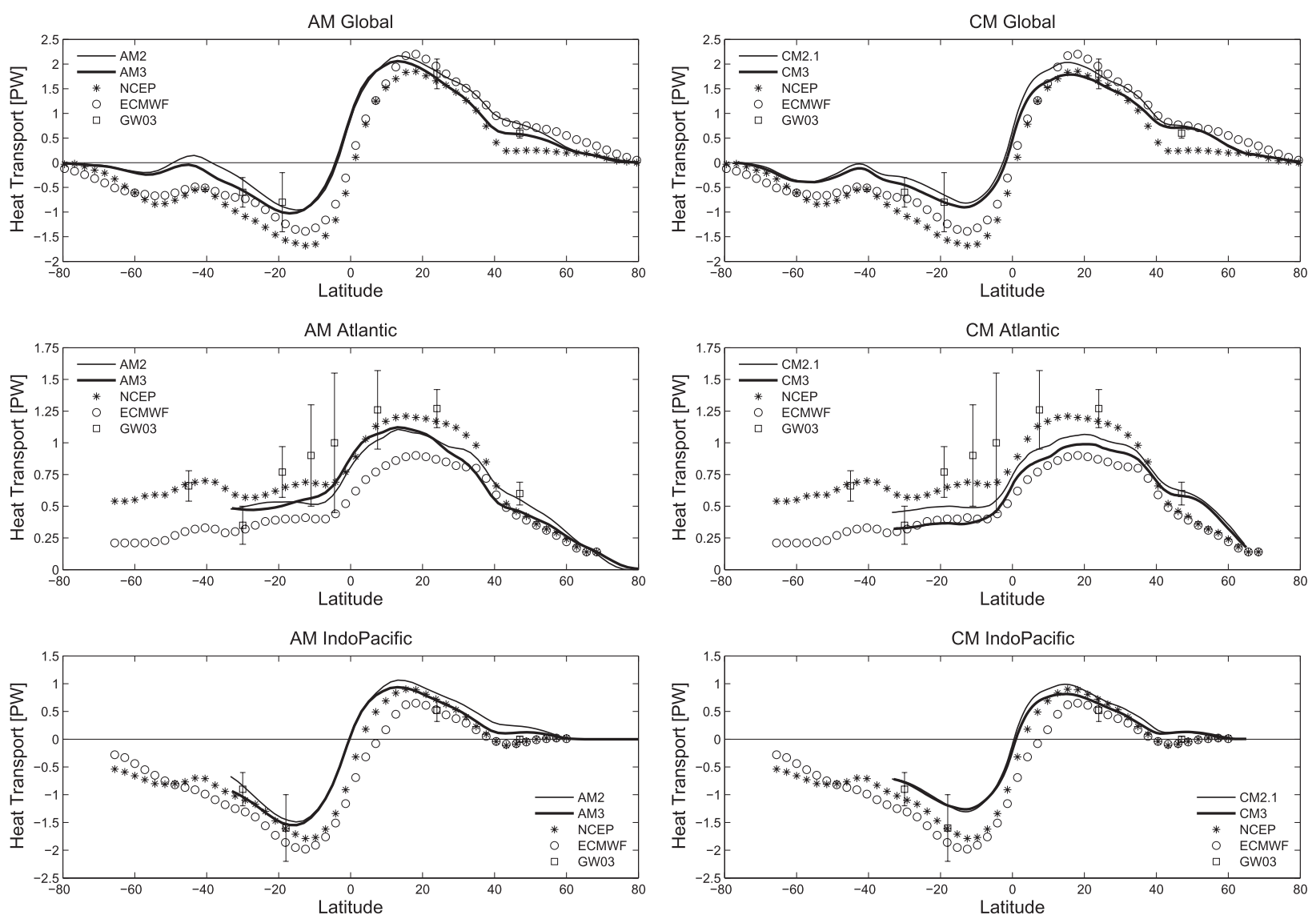

FIG. 5. (left) Implied ocean heat transport for the atmosphere-land models AM2-LM2 and AM3-LM3, when run in AMIP mode (Gates 1993), for the global, Atlantic, and Indo-Pacific basins. Results are computed as time means over simulations years 1983-98. The net imbalances are $0.51 \mathrm{~W} \mathrm{~m}^{-2}$ for AM2 and $0.56 \mathrm{~W} \mathrm{~m}^{-2}$ for AM3, with the imbalances removed prior to computing the poleward transports shown here. (right) Ocean heat transport for the coupled models CM2.1 and CM3 from ensemble means over simulation years 1981-2000. Observational estimates are also shown in all figures from in situ measurements analyzed by Ganachaud and Wunsch (2003) and the reanalysis estimates from Trenberth and Caron (2001) (using the period February 1985 to April 1989) from both the NCEPNational Center for Atmospheric Research (NCAR) (Kalnay et al. 1996) reanalysis and the 40-yr European Centre for Medium Range Weather Forecasts reanalysis (ERA-40), Uppala et al. 2005). Note the different scales for the vertical axes in each basin.

transport in the North Pacific is associated with an increase in shortwave absorption in AM3 and CM3, shown in Fig. 3, with this increased radiation extending eastward from East Asia. The bias reduction in shortwave radiation is attributed to an improved treatment of aerosols and clouds in AM3 (Donner et al. 2011).

\section{3) North AtLANTiC}

A dominant pattern of North Atlantic SST bias is the cold spot east of Newfoundland and a warm bias next to the east coast of North America. This bias is associated with a poor representation of the North Atlantic Current as it extends northward from the Gulf Stream. Given the strong SST gradients in this region, a slight shift in the simulated current leads to a strong bias. There are related warm biases also found near southern Greenland. In a broad sense, both CM2.1 and CM3 have cool SSTs in the North Atlantic, with CM2.1 cooler north of $40^{\circ} \mathrm{N}$.

\section{4) SOUTHERN OCEAN}

The reduced Southern Ocean bias in AM3 and CM3 atmospheric radiation (see Fig. 3) results in a reduction in the Southern Ocean warm bias in CM3 relative to CM2.1 (Fig. 2). However, reduction in Southern Ocean SST warm biases are not as dramatic as may be expected based on the changes in shortwave heating. The reason relates to the warmth built into the CM3 initial conditions (section 1a). This heat penetrates to the deep ocean predominantly through the North Atlantic deepwater formation regions and it is transported southward with the overturning circulation (see Fig. 14 discussed in section 3a). By 1981 of the historical experiments, this 


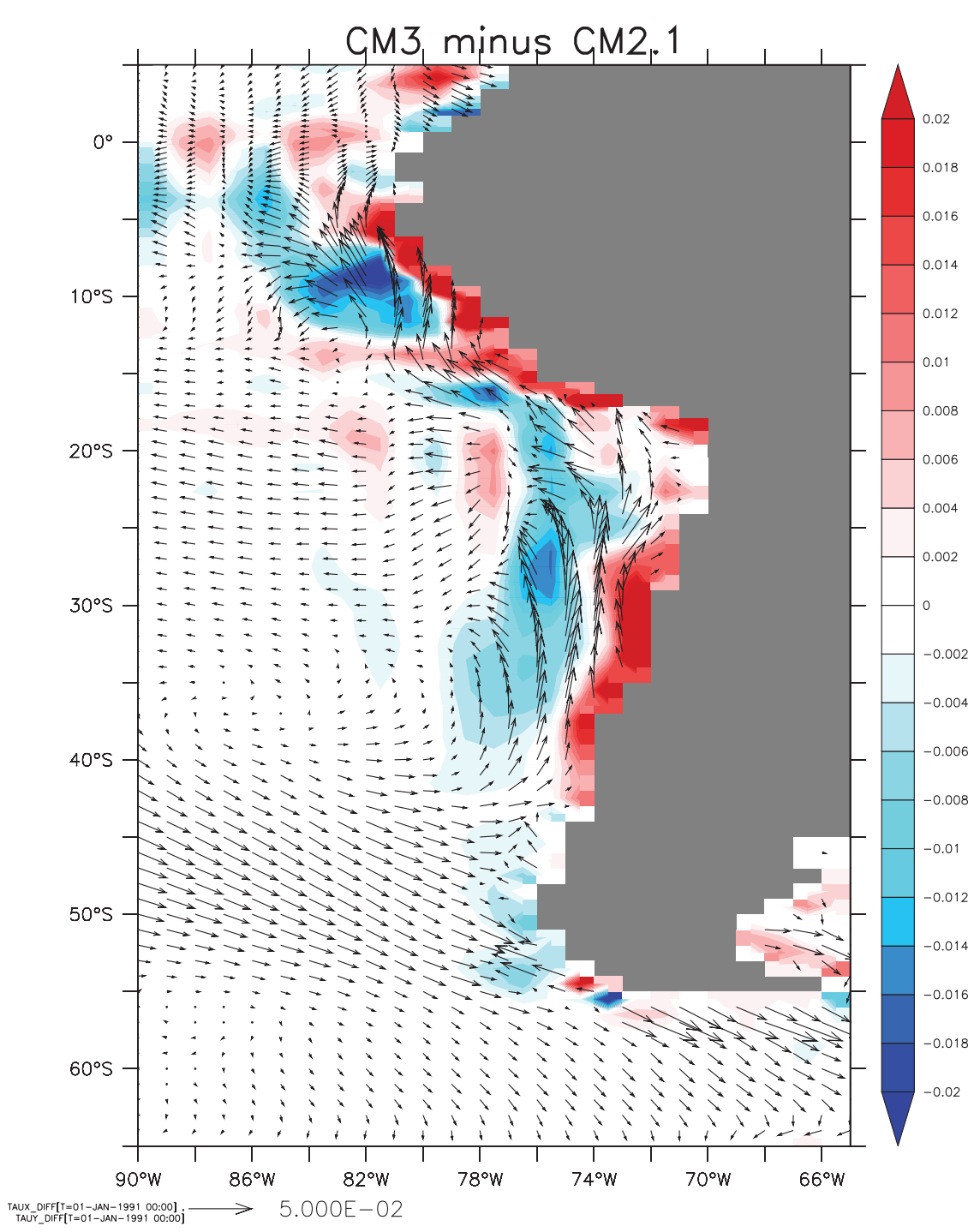

FIG. 6. Difference in the vertical transport (shaded) averaged over upper $100 \mathrm{~m}$ from the ensemble mean of CM2.1 and CM3 over simulation years 1981-2000. Vectors on top of the vertical transport represent the difference in wind stress acting on the ocean. We focus here on the east Pacific region next to South America where the enhanced coastal upwelling in CM3 leads to a smaller SST warm bias than in CM2.1 (Fig. 2).

heat reemerges to the Southern Ocean surface, thus impacting SST biases in the Southern Ocean.

\section{5) NORTH PACIFIC}

The increased radiative heating of the North Pacific in CM3 helps to counteract the cold North Pacific bias found in CM2.1, which was associated with excessive sea ice cover (see Fig. 9 discussed in section 2c). As a result, the broadly cool North Pacific in CM2.1 has been pushed back in CM3 to a weaker bias of the North Pacific gyre, with a slight warming along the coast of North America.

\section{6) West coast of AmericA And AfricA}

Both CM3 and CM2.1 exhibit warm biases off the west coast of the midlatitude Americas as well as Africa. However, there is a noticeable reduction in this bias for CM3, especially next to South America. As seen in Fig. 6, the reduction in warm bias off South America is associated with stronger upwelling of cold water near the coast, driven by stronger equatorward wind stress creating stronger Ekman divergence. There is also a slight increase in upwelling off the coast of West Africa in CM3 (not shown). 

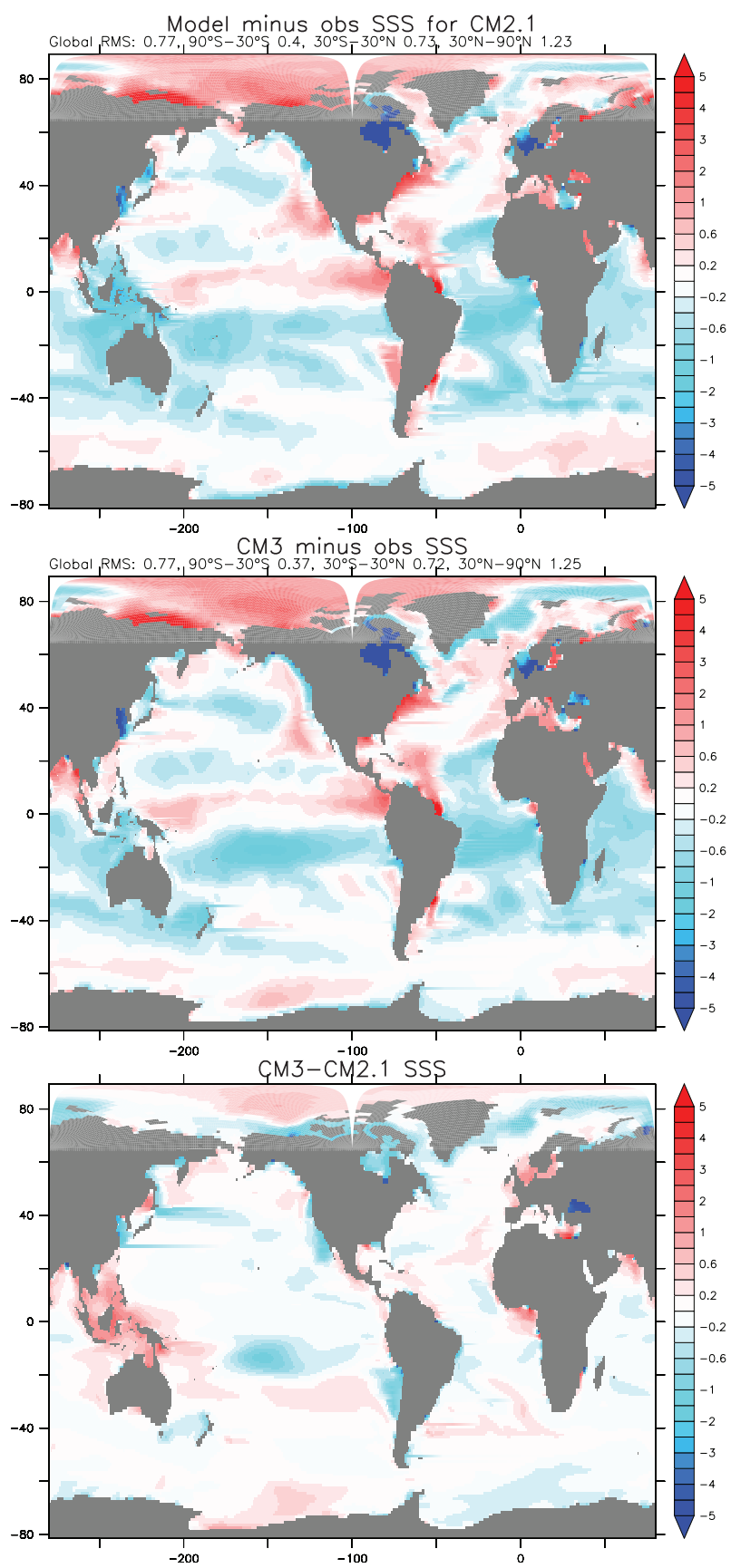

FIG. 7. Ensemble mean sea surface salinity for CM2.1 and CM3 model years 1981-2000, minus the climatology from Steele et al. (2001). The rms error is noted at the top of the figure, with these numbers computed for all ocean regions, excluding the Hudson Bay. These values for the errors are summarized as follows: CM2.1: Global $=0.77,90^{\circ}-30^{\circ} \mathrm{S}=0.40,30^{\circ} \mathrm{S}-30^{\circ} \mathrm{N}=0.73,30^{\circ}-90^{\circ} \mathrm{N}=1.23$; and CM3: Global $=0.77,90^{\circ}-30^{\circ} \mathrm{S}=0.37,30^{\circ} \mathrm{S}-30^{\circ} \mathrm{N}=0.72,30^{\circ}-$ $90^{\circ} \mathrm{N}=1.25$. The difference between CM3 and CM2.1 SSS is also shown, with these differences far smaller in magnitude than the differences from the observed climatology.
Stronger equatorward winds along the west coast of South America are part of an enhanced subtropical high pressure in the southern portion of the east Pacific, also associated with enhanced solar radiation (not shown). Additionally, there are potentially important differences in the atmospheric model grid arrangement and orography representation that may affect how coastal wind stresses impact the ocean: (i) the representation of the Andes is taller (and more realistic) in the AM3 configuration; (ii) the AM3 model grid is slightly finer with the zonal resolution in $\mathrm{AM} 3$ roughly $1.875^{\circ}$, whereas it is $2.5^{\circ}$ in AM2; and (iii) the AM3 grid is better aligned with the ocean grid, thus allowing for a transfer of fluxes between atmosphere and ocean to occur on a finer grid that provides less diffusion from grid averaging.

\section{b. Sea surface salinity}

As for SST biases, the sea surface salinity (SSS) bias patterns reflect accuracy of the coupling between the ocean and other climate model components, as well as ocean circulation, with primary importance placed on the hydrological cycle. Given the very different feedback mechanisms impacting SST versus SSS (see, e.g., Griffies et al. 2009b), it is useful to investigate both fields when characterizing the physical integrity of a simulation.

As the ocean models in CM2.1 and CM3 use real water fluxes, the global mean ocean salinity is modified through changes in ocean volume (through precipitation, evaporation, river runoff, and sea ice formation/melt), as well as exchange of salt with the sea ice model. These effects are relatively small, thus leaving the global mean salinity throughout the simulations quite close to the initial value of 34.72 psu taken from Steele et al. (2001). However, as for temperature, patterns of change in ocean salinity are important, as they provide a signature of problems with the boundary hydrological forcing and surface ocean currents. Figure 7 shows the climatological SSS difference from observations taken over model years 1981-2000. We now identify certain notable features in the SSS bias maps.

\section{1) INLAND SEAS}

There is a large fresh bias in Hudson Bay, the North Sea, and the East Asian marginal seas for both CM2.1 and $\mathrm{CM} 3$. Each of these biases reflects on the difficulty in a coarse-resolution model of representing estuarine processes, requiring substantially finer grid resolution and exchange with the open ocean. For the Hudson Bay and Baltic Sea, which are landlocked in the ocean model owing to insufficient grid resolution, we employ the exchange scheme described by Griffies et al. (2005). The SSS biases for these regions expose limitations of this scheme, though we note that the more modest biases in 

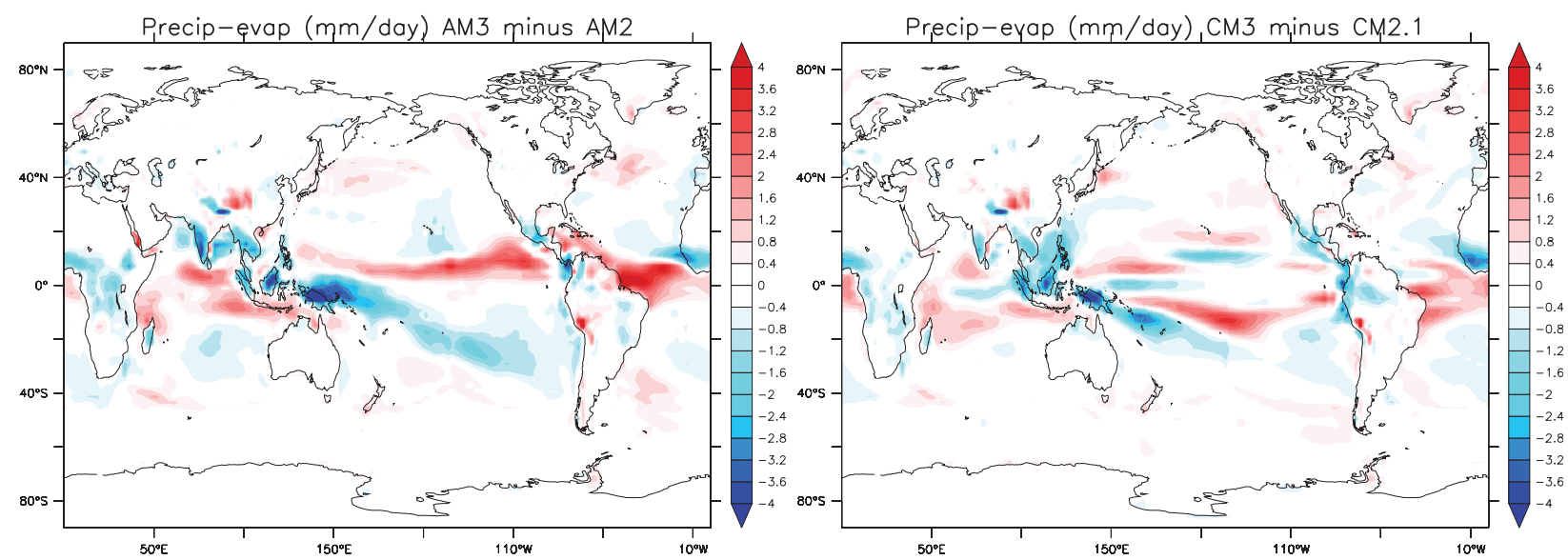

FIG. 8. Difference in precipitation minus evaporation between AMIP simulations using AM3-LM3 and AM2-LM2, as well as the same differences from years 1981-2000 from the ensemble means of CM3 minus CM2.1. Note the enhanced precipitation in AM3 and CM3 within the tropical Atlantic region and the reduced precipitation over Indonesia.

the Mediterranean Sea illustrate that the scheme has some utility for this particular marginal sea.

\section{2) ARCTIC OCEAN}

There is a salty bias in the Arctic basin in both CM2.1 and CM3. There is some indication that the biases are larger near the shelves north of Siberia. The cause of this bias is the subject of ongoing research.

\section{3) Tropical AND SUbTropicAl OCEANS}

There is a fresh bias in most of the subtropical oceans, with the exception of the Atlantic, which exhibits a salty bias arising from the weaker than observed outflow from the Amazon River. The fresh bias over the Indonesian Archipelego in CM2.1 has been reduced in CM3, with this reduction associated with a reduction in precipitation minus evaporation in both $\mathrm{AM} 3$ and $\mathrm{CM} 3$, as seen in Fig. 8.

\section{4) North Atlantic}

As discussed in Delworth et al. (2006), Griffies et al. (2005), and Gnanadesikan et al. (2006), high-latitude fresh biases were of concern during the development of CM2.1, as they can weaken or destabilize the overturning circulation. This concern motivated development of the tide mixing scheme of Lee et al. (2006), which reduced the North Atlantic fresh biases in CM2.1. As seen in Fig. 7, SSS biases in the North Atlantic are slightly salty near North America, though there is a notable fresh bias extending southward along the East Greenland Current from the Arctic. Both models display a strong salty bias centered near northeast South America, with this bias associated with a weak outflow from the Amazon River.

\section{5) SOUTHERN OCEAN}

SSS biases in the Southern Ocean are minor relative to those in the remainder of the World Ocean, with both models exhibiting a slight salty bias except near the Antarctic coast. Near the coast there is a slight fresh bias, especially in the Ross Sea. This bias may be related to the treatment of land-ice calving, which is dumped at the land-sea boundary without the transfer of icebergs away from land as occurs in nature.

\section{c. Sea ice coverage and thickness}

The simulation of sea ice provides another important surface ocean field that reflects on the integrity of the high-latitude fluxes of momentum and buoyancy, with realistic sea ice extent a critical element in the use of a climate model for studying high-latitude climate change. Figure 9 shows the bias in CM2.1 and CM3 climatological annual mean sea ice extents for the ensemble mean during simulation years 1981-2000. The following highlights salient aspects of sea ice in the two simulations.

\section{1) North AtLantic AND ARctic}

The overly large sea ice extent in the North Atlantic seen in CM2.1 remains a problem in CM3. Both model biases are related to the weaker than observed poleward heat transport in the Atlantic (Fig. 5).

Arctic sea ice coverage has been the focus of much research in recent years, given the potential for an icefree period to appear in the Arctic within the next few decades (Serreze et al. 2007). The climatological seasonal cycle of ice area is shown in Fig. 10. CM2.1 and CM3 have roughly the same annual mean ice cover, and their values correspond reasonably well to the observational estimate from Cavalieri et al. (2003). However, 

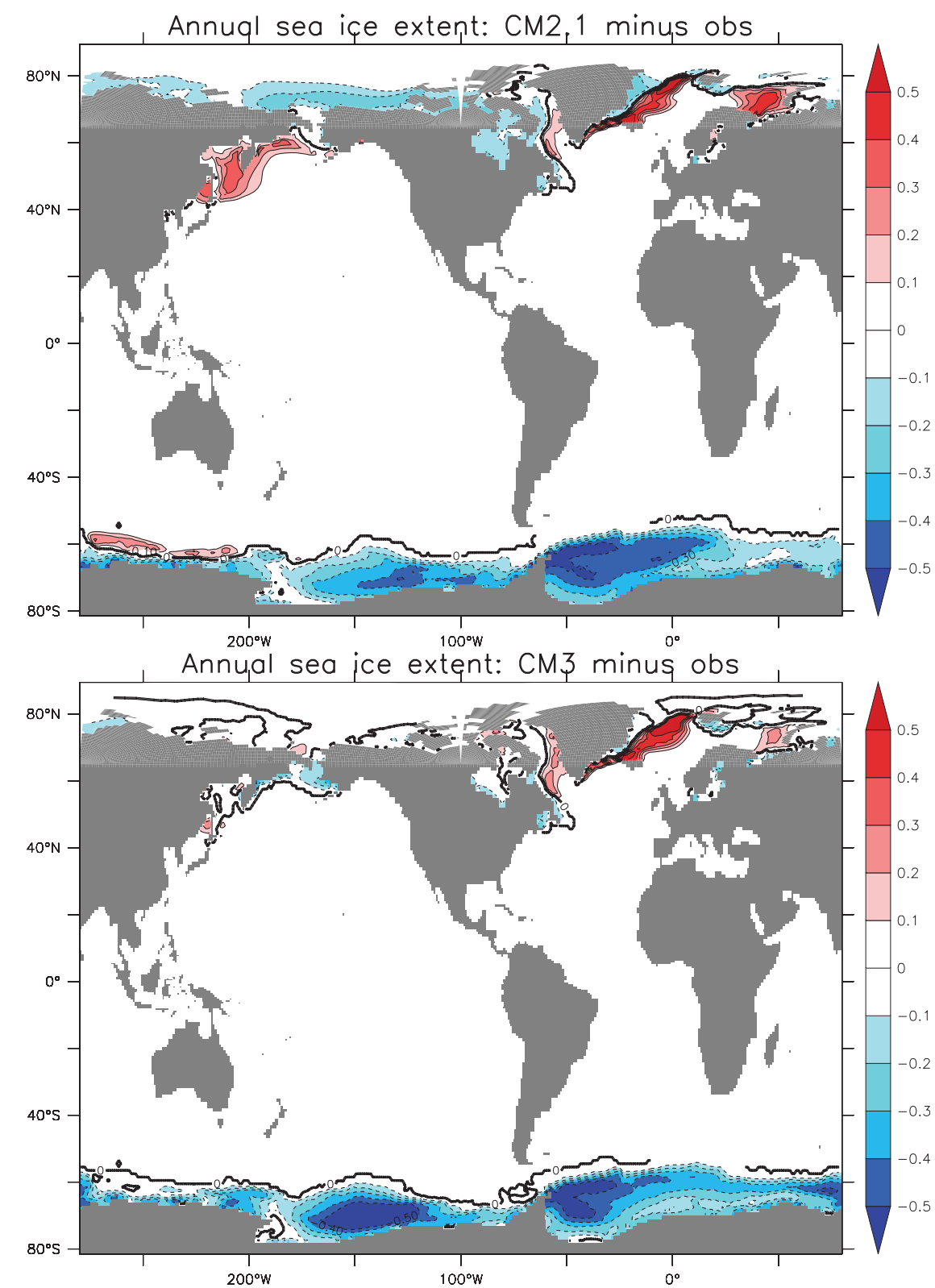

FIG. 9. Maps of the annual mean and ensemble mean sea ice extent from CM2.1 and CM3 (averaged over years 1981-2000) minus a sea ice extent climatology based on observations. The observed ice extent climatology is computed from the monthly sea ice concentrations for years 1981-2000 made available by NCAR and was constructed following the procedure described by Hurrell et al. (2008). Sea ice extent is defined to be unity if the ice concentration is more than $15 \%$ for a gridcell area and zero if there is less ice in a cell. Values between zero and one arise from time averaging. Note the reduced sea ice extent from CM3 in the North Pacific, whereas both CM2.1 and CM3 show far too much sea ice in the Greenland Sea. Some changes also arise in the Southern Ocean, though both models show generally too low ice cover there, which is partly associated with the warm SST bias in the south (see Fig. 2).

the seasonal cycles are different, with CM3 exhibiting an increase in summertime ice and a reduction in wintertime ice. Both changes represent an improvement in the simulation of the Arctic climate in $\mathrm{CM} 3$, agreeing quite well with the satellite observations from Fetterer et al. (2009).

The Arctic sea ice thickness in CM2.1 is quite thin relative to other AR4 climate models Holland et al. (2008), 

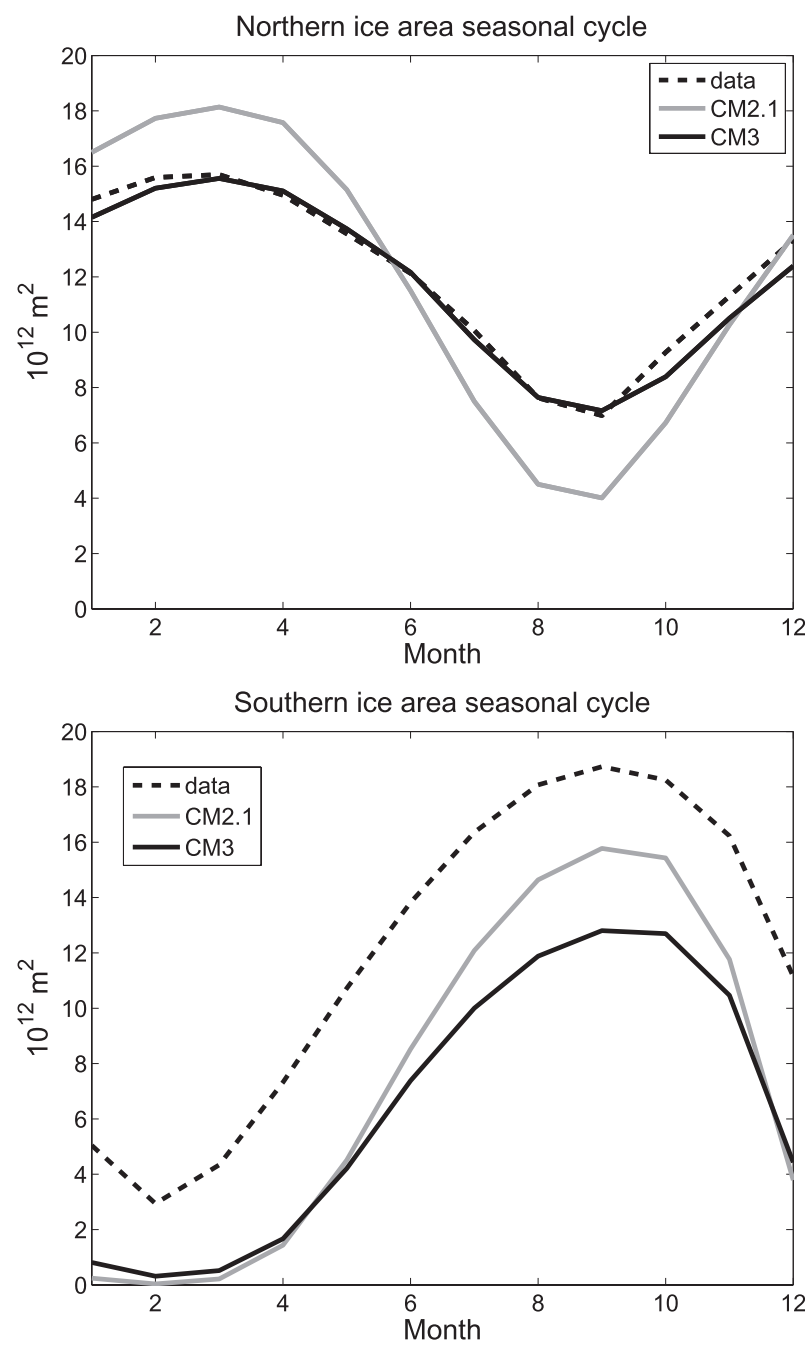

FIG. 10. Climatological seasonal cycle computed from the ensemble mean over years 1981-2000 for CM3 and CM2.1 in the Northern Hemisphere and Southern Hemisphere. Observational estimates for the seasonal cycle from Fetterer et al. (2009) are shown by the dashed lines. Observational estimates for the annual means from Cavalieri et al. (2003) are roughly $12 \times 10^{12} \mathrm{~m}^{2}$ for the Northern Hemisphere and $11.5 \times 10^{12} \mathrm{~m}^{2}$ for the Southern Hemisphere. The annual means for the simulations are for the Northern Hemisphere: CM3 $=12.4 \times 10^{12} \mathrm{~m}^{2}$, CM2.1 $=13.5 \times$ $10^{12} \mathrm{~m}^{2}$; and for the Southern Hemisphere: CM3 $=4.4 \times 10^{12} \mathrm{~m}^{2}$, $\mathrm{CM} 2.1=3.8 \times 10^{12} \mathrm{~m}^{2}$.

see their Fig. 2). While observations of sea ice thickness are scarce, CM2.1 is very thin relative to the available observational estimates. For example, Kwok and Rothrock (2009) show thickness of about $2 \mathrm{~m}$ in September near the North Pole based on submarine and satellite data. Annual mean thickness in this region is close to $1 \mathrm{~m}$ in CM2.1 (Fig. 11). In CM3 this thickness is increased to about $2 \mathrm{~m}$, in better agreement with the observed values. The pattern of ice thickness in CM3 is in good agreement with observations from Bourke and Garrett (1987).
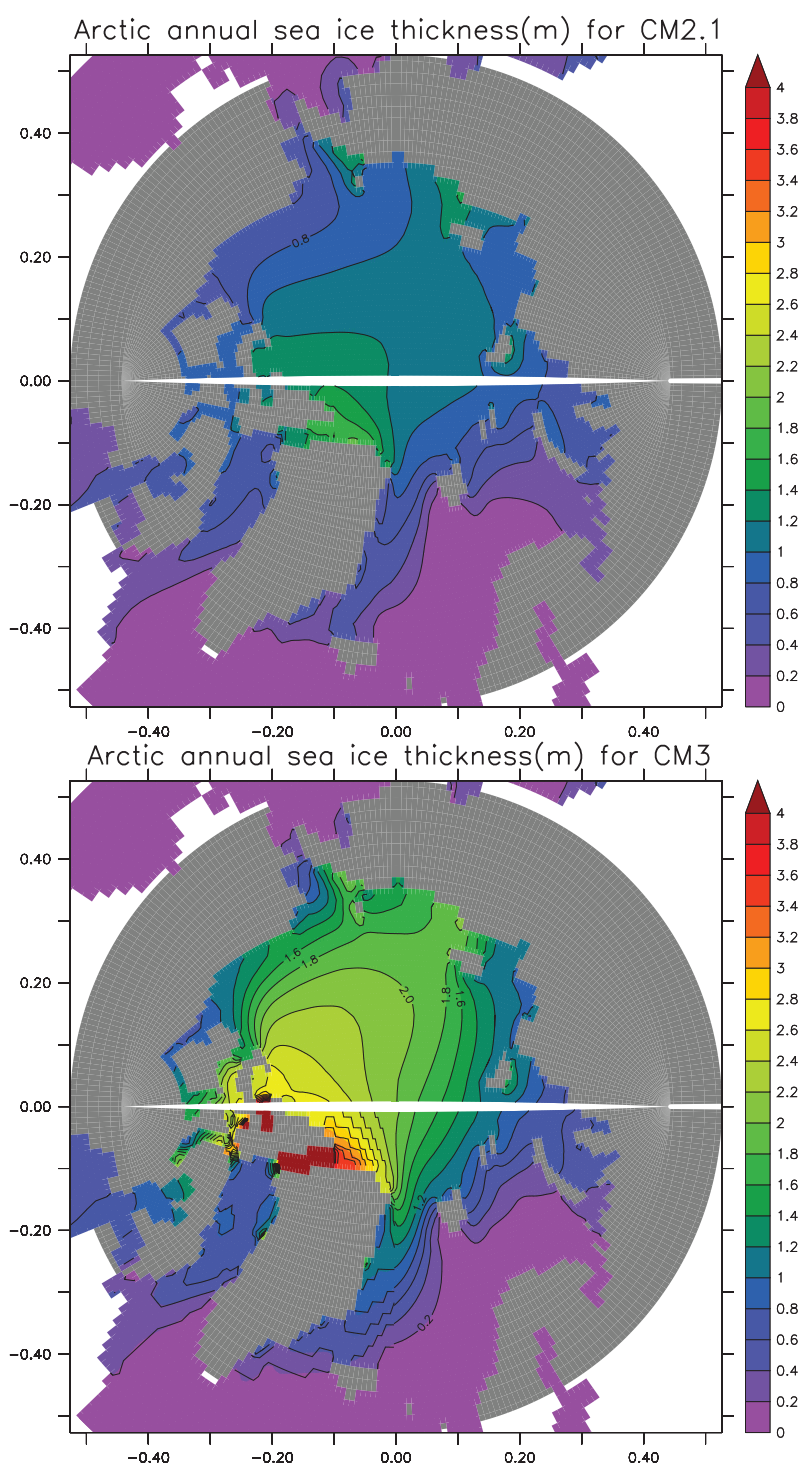

FIG. 11. Maps of the annual mean sea ice thickness (m) from CM2.1 and CM3, as averaged over model years 1981-2000. Note the enhanced thickness in CM3. Also note that the white line across the Arctic is an artefact of the plotting software arising from the use of a nonspherical grid for regions poleward of $65^{\circ} \mathrm{N}$.

While increased (and more realistic, see Table A1 in the appendix) albedo has increased the thickness in $\mathrm{CM} 3$, some improvement in the pattern is also due to a better simulation of Arctic sea level pressure, as shown in Fig. 12 (see also Donner et al. 2011). An overly extensive anticyclonic gyre extending into the eastern Arctic Ocean is a common problem with climate model sea ice motion that can be traced to biases in simulations of Arctic sea level pressure patterns (Bitz et al. 2002). Figure 12 shows that the simulation of Arctic sea level pressure in CM3 is significanly improved over that of CM2.1. This improvement may be related to the 

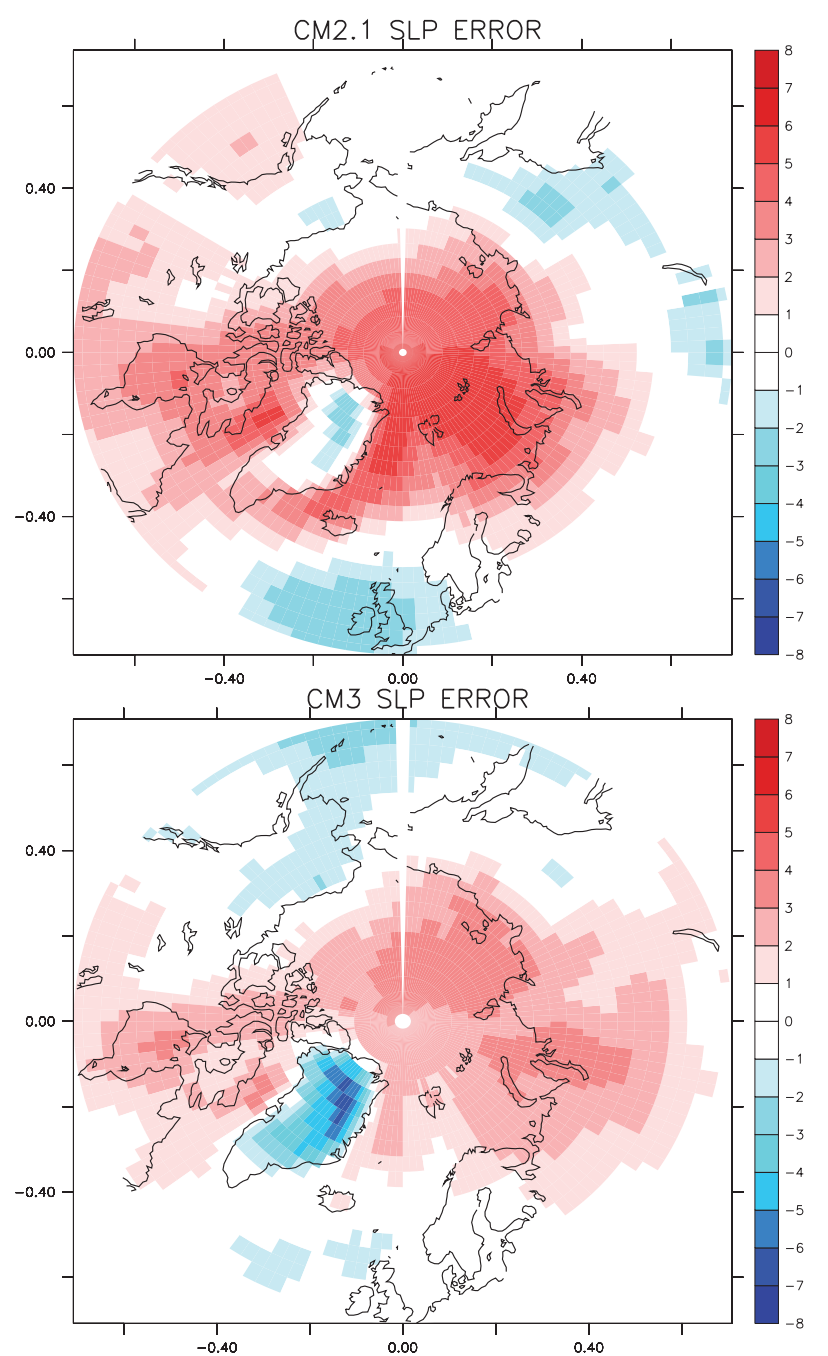

FIG. 12. Maps of the Arctic sea level pressure biases computed as the ensemble mean and time mean (years 1961-2000) for the climate models as differenced from the NCEP-NCAR reanalysis climatological mean for years 1958-1997 (Kalnay et al. 1996). Note the reduced biases over the CM3 Arctic Ocean. Also note that the increased negative bias in CM3 over Greenland has no impact on the sea ice.

improvement in the positive ice bias in the Barents Sea (Fig. 9).

\section{2) North PACIFIC}

The North Pacific in CM2.1 had an overabundance of winter sea ice, as evidenced by the bias in Fig. 9. This positive ice bias is consistent with the cold SST bias shown in Fig. 2. As previously discussed, the North Pacific cold bias has largely been eliminated in CM3 with the warmer SSTs reducing the sea ice bias. Indeed, the bias has been reduced sufficiently to allow for the use of more realistic (i.e., larger) sea ice albedos in CM3 than CM2.1 (see Table A1 in the appendix).

\section{3) SOUTHERN OCEAN}

In the Southern Hemisphere both models greatly underestimate the annual mean sea ice area, with a near elimination of summer ice (Fig. 10). This low bias in the summer is slightly reduced in CM3, perhaps due to the increase in sea ice albedo in CM3 (see Table A1 in the appendix). However, there is less wintertime ice in CM3. Hence, both models exhibit a low bias in sea ice cover that is associated with the warm SST biases in the Southern Ocean (Figs. 2 and 4).

\section{d. Sea level patterns and biases}

Dynamic sea level (DSL) provides information about sea level deviation from the geoid, with this field closely linked to ocean currents, surface thermohaline fluxes, and the density structure and mass distribution throughout the entire ocean domain. ${ }^{2}$ The modeled DSL is compared with a DSL climatology formed by combining observations of satellite altimetry, surface currents, and winds with an approximation of the earth's geoid from satellite gravity measurements (Maximenko and Niiler 2005). Although the ocean model components of CM2.1 and CM3 are formulated using the Boussinesq approximation for which volume rather than mass is conserved in the absence of net boundary fluxes, the simulated DSL can realistically represent the horizontal gradient of sea level with a globally constant adjustment approximating the more accurate non-Boussinesq sea level (Greatbatch 1994). Besides being of interest for climate change science, an analysis of sea level provides a general overview of the large-scale features of the ocean circulation found in CM2.1 and CM3.

In the presence of sea ice, the ocean free surface is depressed. Consequently, we are more interested in the sea surface height that incorporates the equivalent water from sea ice,

$$
h(x, y, t)=\eta(x, y, t)+\frac{M^{\text {ice }}(x, y, t)}{\rho_{o}},
$$

where $\eta$ is the free surface height of liquid water computed by the ocean model, $M^{\text {ice }}$ is the mass per unit area of sea ice, and $\rho_{o}=1035 \mathrm{~kg} \mathrm{~m}^{-3}$ is the reference density for the Boussinesq approximation. ${ }^{3}$ It is $h$, as defined here, that we refer to as the DSL in the following.

\footnotetext{
${ }^{2}$ The geoid defines the static sea level, whose geometry is determined by the mass distributions and rotational properties of the earth. We take the geoid to be equal to the ocean model surface $z=0$.

${ }^{3}$ The ocean models in CM2.1 and CM3 compute the free surface, $\eta$, according to the explicit free surface method of Griffies et al. (2001).
} 
The mean DSL based on observations from Maximenko and Niiler (2005) is shown in Fig. 13. Simulations of the mean DSL by CM2.1 and CM3 display many of the same large-scale features as the observed. Indeed, when compared to other models participating in the third Coupled Model Intercomparison Project (Meehl et al. 2007), the analysis of Yin et al. (2010a) reveals that CM2.1 has one of the smallest DSL rms errors among the suite of climate models. By comparison, CM3 also remains among the better models based on this metric.

The DSL is very low in the Labrador, Irminger, and Nordic Seas, with this low associated with subpolar cyclonic circulations and North Atlantic Deep Water (NADW) formation. DSL is also low in the Southern Ocean because of the strong Antarctic Circumpolar Current (ACC), see section 3d. It is high in the tropical and subtropical Pacific and Indian Oceans, especially toward the western part of ocean basins. The simulated basin mean DSL by CM3 is slightly higher than the observations in the Pacific and Indian Ocean, whereas it is lower than observations in the Atlantic and Arctic Oceans. Generally, the most notable observed DSL features, including a pronounced Atlantic-Pacific DSL difference and a strong equator to pole gradient, are well captured by CM2.1 and CM3.

A large DSL difference between CM2.1 and CM3 occurs in the Southern Ocean near Antarctica, related to the different simulations of the Antarctic gyre systems (not shown). However, the strong meridional gradient in the Southern Ocean is fairly realistic in both simulations. The largest DSL bias in both CM2.1 and CM3 occurs in the Canadian Basin associated with the Beaufort gyre (Fig. 13). Note that this low bias in the Arctic is associated with a salty bias in the surface salinity (Fig. 7). It is partially attributable to the bias of the basinwide DSL. On average, the simulated DSL by CM3 in the Arctic and Atlantic is respectively $0.25 \mathrm{~m}$ and $0.12 \mathrm{~m}$ lower than the observational estimate, a mismatch that may be induced by biased water mass formation and distribution. The mean strength of the AMOC during 1981-2000 is above $20 \mathrm{~Sv}\left(\mathrm{~Sv} \equiv 10^{6} \mathrm{~m}^{3} \mathrm{~s}^{-1}\right)$ in both CM2.1 and CM3 (see Fig. 16 discussed in section 3c), which is somewhat stronger than estimates from observations (Ganachaud 2003; Lumpkin and Speer 2003; Talley 2003, 2008), which in turn leads to a lower simulated Atlantic DSL in both models.

DSL gradients in the zonal direction are generally well simulated, including a skewing of positive DSL toward the western basins in the Atlantic, Pacific, and Indian Oceans, with the highest DSL value found in the northwestern Pacific. The DSL exhibits a sharp gradient across the strong and narrow western boundary currents such as the Gulf Stream and Kuroshio. So, along $30^{\circ} \mathrm{N}$
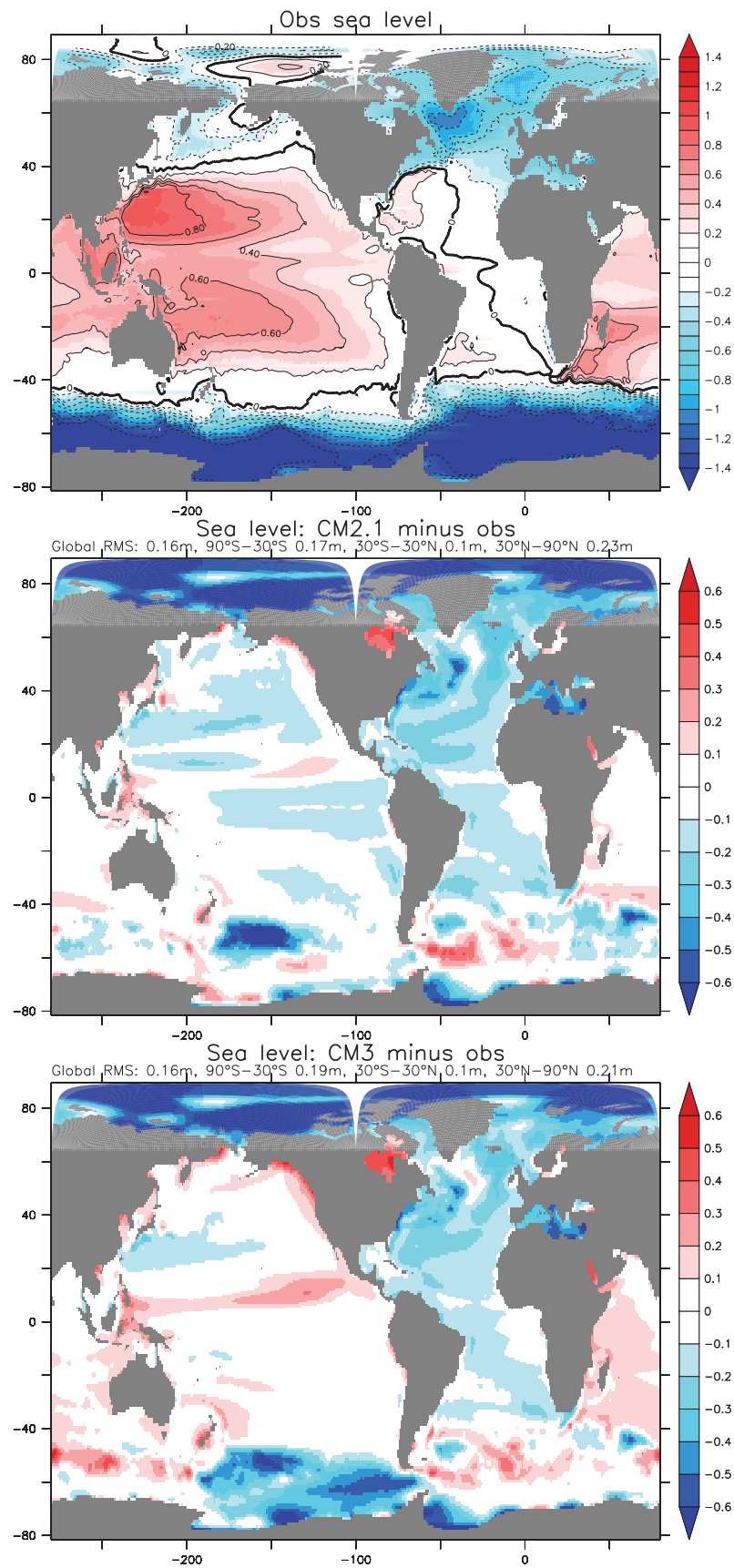

FIG. 13. Comparison of ensemble mean dynamic sea level averaged over years 1981-2000 in CM2.1 and CM3, and the analyzed observations from Maximenko and Niiler (2005). Shown here is the effective sea level defined according to Eq. (1). (top) Global and regional rms errors are listed and are summarized as CM2.1: Global $=0.16 \mathrm{~m}, 90^{\circ}-30^{\circ} \mathrm{S}=0.17 \mathrm{~m}, 30^{\circ} \mathrm{S}-30^{\circ} \mathrm{N}=0.10 \mathrm{~m}, 30^{\circ}-$ $90^{\circ} \mathrm{N}=0.23 \mathrm{~m}$ and $\mathrm{CM} 3$ : Global $=0.16 \mathrm{~m}, 90^{\circ}-30^{\circ} \mathrm{S}=0.19 \mathrm{~m}$, $30^{\circ} \mathrm{S}-30^{\circ} \mathrm{N}=0.10 \mathrm{~m}, 30^{\circ}-90^{\circ} \mathrm{N}=0.21 \mathrm{~m}$.

and $30^{\circ} \mathrm{S}$ the DSL is characterized with a rapid increase and a subsequent gradual decrease in each ocean basin. Similarity between the simulated and observed DSL 

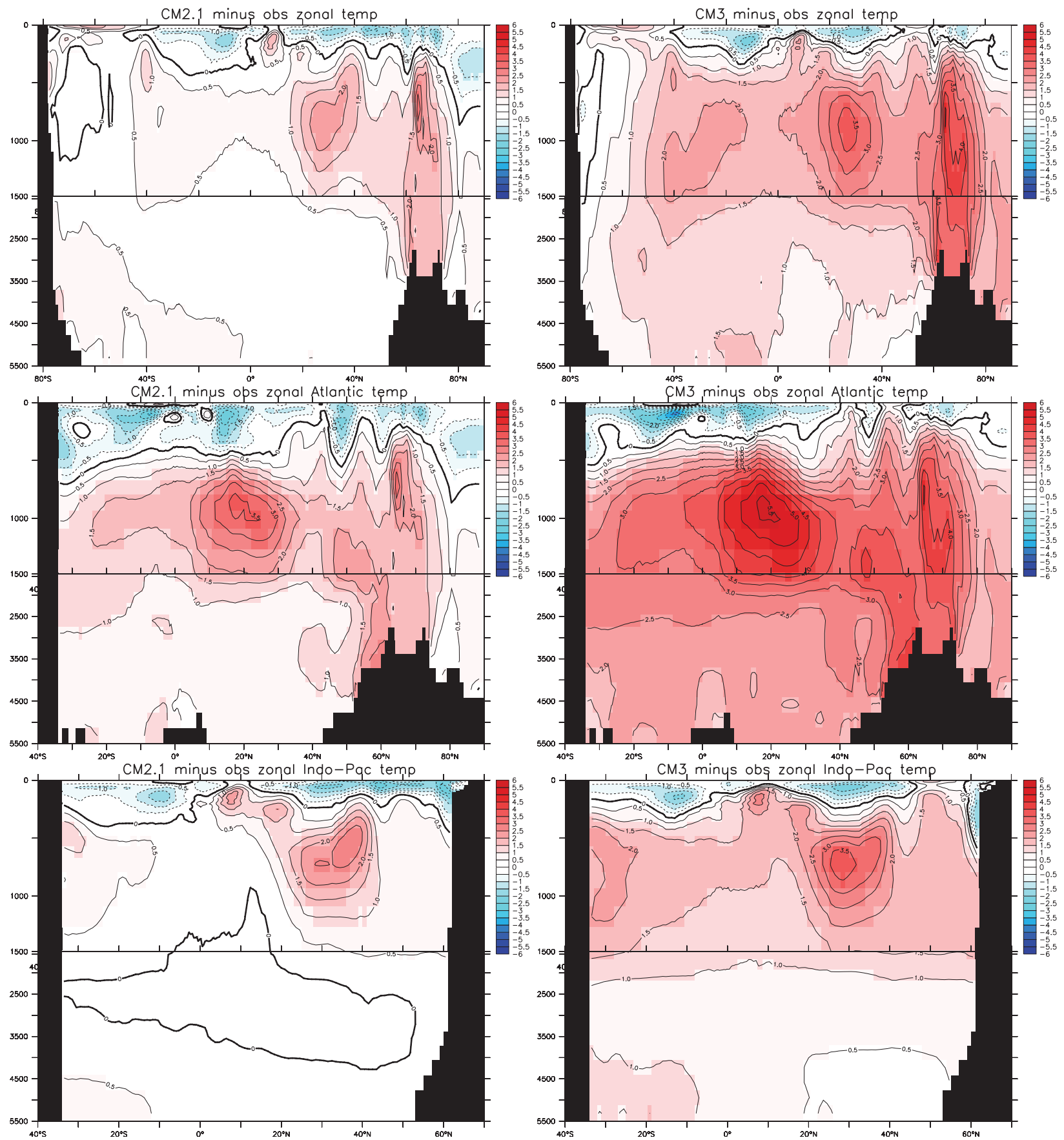

FIG. 14. Biases in zonal mean potential temperature, computed as the ensemble mean from CM2.1 and CM3 over years 1981-2000, and differenced from the climatology of Steele et al. (2001). Note the generally warmer biases in CM3, with the dominant biases in the Atlantic basin, where ventilation in the north is the main pathway for heat to penetrate to the deep ocean. The vertical axis is stretched in the upper $1500 \mathrm{~m}$. After subtracting the mean from the respective anomaly patterns, the spatial correlations between the two models are the following: Global $=0.84$, Atlantic $=0.95$, and Indian-Pacific $=0.84$.

suggests realistic simulations, at least for this class of noneddying models, of the western boundary currents and subtropical gyre circulation in both CM2.1 and CM3. In the high-latitude North Atlantic, the bowl shape of the DSL associated with the subpolar gyre is pronounced. Meanwhile, the simulated DSL in Hudson Bay is too high, resulting from a fresh bias in CM2.1 and CM3 (Fig. 7). The east-west DSL gradient at the equator is of importance for the equatorial current system and for El Niño variability. Although the simulation is close to 
the observational estimate at many longitudes along the equator, a positive deviation is evident in the western equatorial Pacific warm pool region.

\section{e. Summary of surface properties}

In general, surface ocean and sea ice properties in CM3 are about as good, if not improved, relative to CM2.1. The changes in SST biases, in particular a reduction in warm biases next to South America, can largely be attributed to improvements in the atmospheric model found in AMIP simulations. The overall improved atmospheric climatology with AM3 in turn allowed for the use of more realistic sea ice albedos that, along with the SST bias reduction in the North Pacific and improved Arctic sea level pressure patterns, rendered an improved sea ice simulation in the Arctic. The sea surface salinity in CM3 is largely the same as in CM2.1, though there are some changes associated with modifications of the precipitation patterns in AM3 relative to AM2 (see Fig. 8). Increased freshening in the North Atlantic led, in early versions of CM3, to a concern that the overturning circulation may trend to an unrealistically weak state. However, this concern was not borne out, as evidenced by the strong overturning shown in Fig. 16 (see section 3c). Finally, a characterization of the sea level patterns in CM2.1 and CM3 rendered a broad overview of the large-scale currents in the two models.

\section{Interior properties and volume transports}

The purpose of this section is to expose some of the interior temperature and salinity patterns found in the ensemble mean during simulation years 1981-2000. As expected, many of the differences between the models arise from the different initial conditions, discussed in section 1a. Additional warming arises in $\mathrm{CM} 3$ relative to CM2.1 owing to an increase in net heating of the ocean associated with differences in the atmospheric and land components, as revealed in Fig. 1.

The interior biases are largely the result of the transport of heat and salt signals from the surface into the interior and laterally throughout the ocean basins. We quantify aspects of such mass transport (or volume transport in a Boussinesq model) for selected straits and throughflows in this section, as well as discuss spatial and temporal features of the overturning circulation.

\section{a. Temperature and salinity bias patterns}

Figures 14 and 15 show the latitude-depth zonal mean bias patterns for temperature and salinity. The CM3 ocean is much warmer than CM2.1, though the patterns exhibit similar features, as may be expected since the ocean model components are configured the same. These figures reveal the extent to which both models warm due to a combination of ocean heat uptake during model spinup and the heat uptake due to increasing radiative forcing through the twentieth century. CM3, as anticipated, also shows enhanced warming relative to observations owing to the heat built into the initial conditions (section 1a).

To quantify the similarities in the bias patterns, we compute pattern correlations, which are listed in the respective figure captions. For each figure, the correlations are 0.84 or larger, suggesting that the main difference between the oceans is just the magnitude of the temperature and salinity differences with respect to the observations, rather than changes in details of the pathways for these changes. Note in particular that pattern correlations in the Atlantic basin are the highest, with this basin also seeing the largest biases relative to observations.

It is in the Atlantic basin that deep-water formation provides a conduit for warm and salty water to enter the ocean interior. The meridional overturning circulation, as well as other transport processes such as diffusion, then spread this heat southward and downward.

The bias patterns for salinity are comparable between CM2.1 and CM3, though CM3 exhibits slightly larger biases especially in the Atlantic. The increased salinity bias in the Atlantic indicates that the density bias is partially compensated (i.e., warm and salty biases). Both models possess large fresh biases near high-latitude coasts and inland seas, a basinwide salty bias in the Atlantic, and a slight salty bias in the North Pacific gyre.

\section{b. Vertically integrated volume transports}

Table 1 summarizes the volume transports in selected straits and throughflows for the ensemble mean in CM2.1 and CM3 over years 1981-2000. Reference values from observations are given where available. In general, the two simulations remain in broad agreement with observational estimates. In section $3 d$, we further discuss the increased Drake Passage transport in CM3.

\section{c. Meridional overturning circulation}

The time mean meridional-depth overturning circulation MOC depicts the interhemispheric oceanic circulation associated with both wind-driven and thermohaline forcings. The nature of the wind-driven circulation (which can be explained entirely by the surface wind stress) is nearly identical in the two models and gives rise to similar transports. This feature arises from the very similar wind stress patterns found in the two coupled models (Donner et al. 2011). The thermohaline component of the MOC is a consequence of both surface and internal processes and, thus, more difficult to characterize.

Figure 16 shows the time mean (for years 1981-2000) and ensemble mean global and Atlantic overturning 

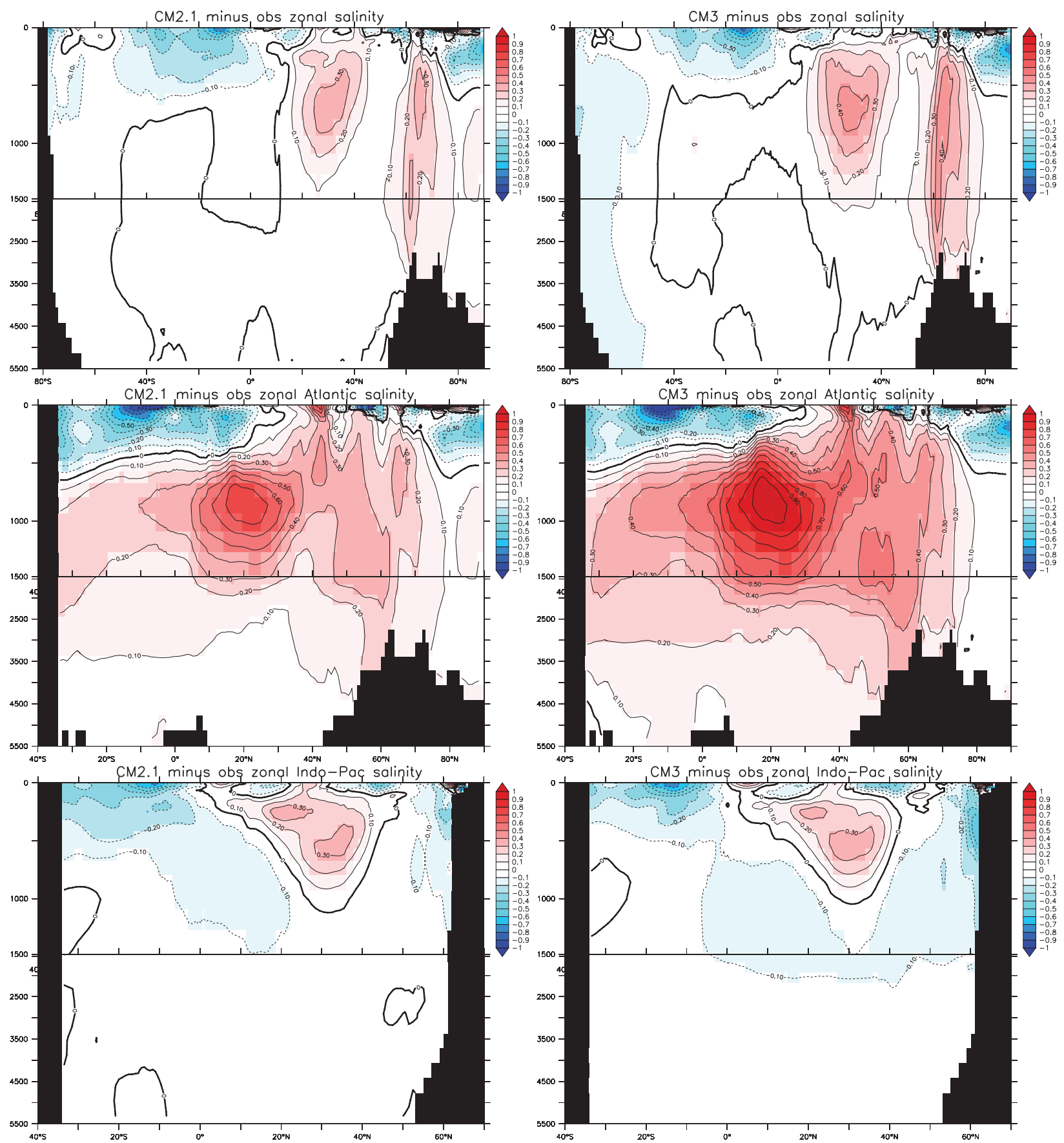

FIG. 15. Biases in zonal mean salinity computed as the ensemble mean from CM2.1 and CM3 over years 1981-2000, and differenced from the climatology of Steele et al. (2001). Note the enhanced biases in the Atlantic basin. The vertical axis is stretched in the upper $1500 \mathrm{~m}$. After subtracting the mean from the anomaly patterns, the spatial correlations between the two models are the following: Global = 0.91 , Atlantic $=0.94$, and Indian-Pacific $=0.86$.

streamfunction for CM2.1 and CM3. Both models exhibit similar overturning streamfunction patterns, with minor differences in the strength of the shallow overturning in the Northern Hemisphere tropical cell and the degree of upwelling in the tropical Atlantic. As shown by
Gnanadesikan et al. (2007), the relatively large cell in the Southern Ocean around $55^{\circ} \mathrm{S}$ (the Deacon Cell) is associated with choices made in the implementation of the ocean mesoscale eddy parameterization. For the Atlantic the downward branch in the north reaches to 
TABLE 1. Volume transports (Sv) through selected straits and currents in CM2.1 and CM3. These values were computed from the ensemble mean of the simulations over years 1981-2000. Directions are noted by n: north, e: east, and s: south. These transports are suggested by the Climate Variability and Predictability (CLIVAR) Working Group for Ocean Model Development for use in the Climate Model Intercomparison Project (Griffies et al. 2009a). Note that some of the differences between model results and observational estimates arise from differences in the model grid resolution. For example, some passages are artificially wider or deeper than observations (e.g., Denmark Strait) so as to allow for a representation of the passage on the coarse model grid.

\begin{tabular}{|c|c|c|c|c|}
\hline Current/Strait & Obs (sv) & Reference & CM2.1 & CM3 \\
\hline Barents opening & $1.5-2.0(\mathrm{n})$ & Ingvaldsen et al. (2004) & 2.5 & 2.0 \\
\hline Bering Strait & $0.8(\mathrm{n})$ & Roach et al. (1995) & 0.8 & 1.0 \\
\hline Davis Strait & $0.7-2(s)$ & Sadler (1976); Fissel et al. 1998; Melling (2000) & 0.6 & 0.7 \\
\hline Denmark Strait & $3(\mathrm{~s})-0.8(\mathrm{n})$ & Osterhus et al. (2005); Olsen et al. (2008) & $9(\mathrm{~s})$ & $9(\mathrm{~s})$ \\
\hline Drake Passage & $135(\mathrm{e})$ & Cunningham et al. (2003) & 130 & 160 \\
\hline Equatorial undercurrent $\left(155^{\circ} \mathrm{W}\right)$ & $24-36(\mathrm{e})$ & Lukas and Firing (1984); Sloyan et al. (2003) & 30 & 24 \\
\hline Fram Strait & $2-6(s)$ & Schauer et al. (2004) & $2.9(\mathrm{~s})$ & $2.5(\mathrm{~s})$ \\
\hline Indonesian Throughflow & $12(\mathrm{~s})$ & Gordon et al. (2008) & 13 & 15 \\
\hline Mozambique Channel & $5(\mathrm{n})-25(\mathrm{~s})$ & DiMarco et al. (2002) & $16(s)$ & $18(\mathrm{~s})$ \\
\hline Luzon Strait & $3-9(w)$ & Tian et al. (2006) & $7(w)$ & $7(w)$ \\
\hline
\end{tabular}

around $3000-3500 \mathrm{~m}$ in both cases, with CM3 slightly deeper.

The maximum of the Atlantic streamfunction occurs near $45^{\circ} \mathrm{N}$, with the strength about 3-4 Sv larger in $\mathrm{CM} 3$ than CM2.1. However, the poleward heat transport is slightly weaker in CM3 (Fig. 5). Less heat transport with stronger overturning circulation arises in CM3 since there is less top to bottom temperature difference owing to the enhanced warm bias at depth (Fig. 14).

Fluctuations of the overturning circulation in the Atlantic are of special interest for studies of climate variability and predictability. For simulations with constant radiative forcing (either 1860 or 1990), both CM3 and CM2.1 exhibit roughly the same time scale and amplitude of fluctuations in the Atlantic maximum overturning, with around 1.5-2-Sv amplitude and power concentrated around 20 years (not shown). The historical runs are more complex, with the overturning in the two models responding differently to changes in atmospheric greenhouse gas and aerosol forcing, due to the use of different atmospheric models. Such behavior is the topic of ongoing study.

\section{d. Southern Ocean}

The Southern Ocean accomplishes interbasin water exchange via the Antarctic Circumpolar Current, as well as the transformation of inflowing NADW into lighter Subantarctic Mode Water (SAMW) and Antarctic Intermediate Water (AAIW), and into denser Antarctic Bottom Water (AABW). We characterize aspects of CM2.1 and CM3 in the Southern Ocean by exhibiting volume transports in this region. To begin, we note that the volume transport through Drake Passage (Table 1) is statistically stationary (on centennial time scales) for the unforced 1860 and 1990 control simulations, as well as for the ensemble of historical simulations. The zonal mean winds are very similar between CM2.1 and CM3 (Donner et al. 2011). Hence, the stronger Drake Passage transport in $\mathrm{CM} 3$ implies changes in other aspects of the Southern Ocean circulation, such as those setting the meridional density gradient across the ACC. For example, the zonal mean bias pattern in Fig. 14 is enhanced in CM3 within the Southern Ocean, consistent with a stronger baroclinic component to help increase the ACC transport. These circulation and density factors suggest a more convectively active high-latitude Southern Ocean in CM3, which is indeed the case with particularly more deep ventilation in the Ross Sea in CM3 than CM2.1 (not shown).

Russell et al. (2006) and Sloyan and Kamenkovich (2007) described the ability of the IPCC AR4 models to simulate the Southern Ocean mean climate and water mass properties, and both concluded that CM2.1 performed quite well, though not without biases. Sloyan and Kamenkovich showed CM2.1 could reproduce the inverse model transports across the Indian basin, but CM2.1 transports were weaker across the Atlantic and Pacific basins. Russell et al. showed good agreement between the observed and CM2.1 zonal wind strength and position, density gradient across the Southern Ocean, and sea surface temperature. Few of the 18 IPCC models assessed by Russell et al. (2006), including CM2.1, agreed with observational estimates of surface heat fluxes or salinity in the upper $100 \mathrm{~m}$, both of which are important in determining water mass formation rates.

These persistent issues in simulating the Southern Ocean in coupled models prompt us to look at how individual water masses in the Southern Ocean are transported around the globe in the ACC. Here we compare estimates of water mass transports across a section around 

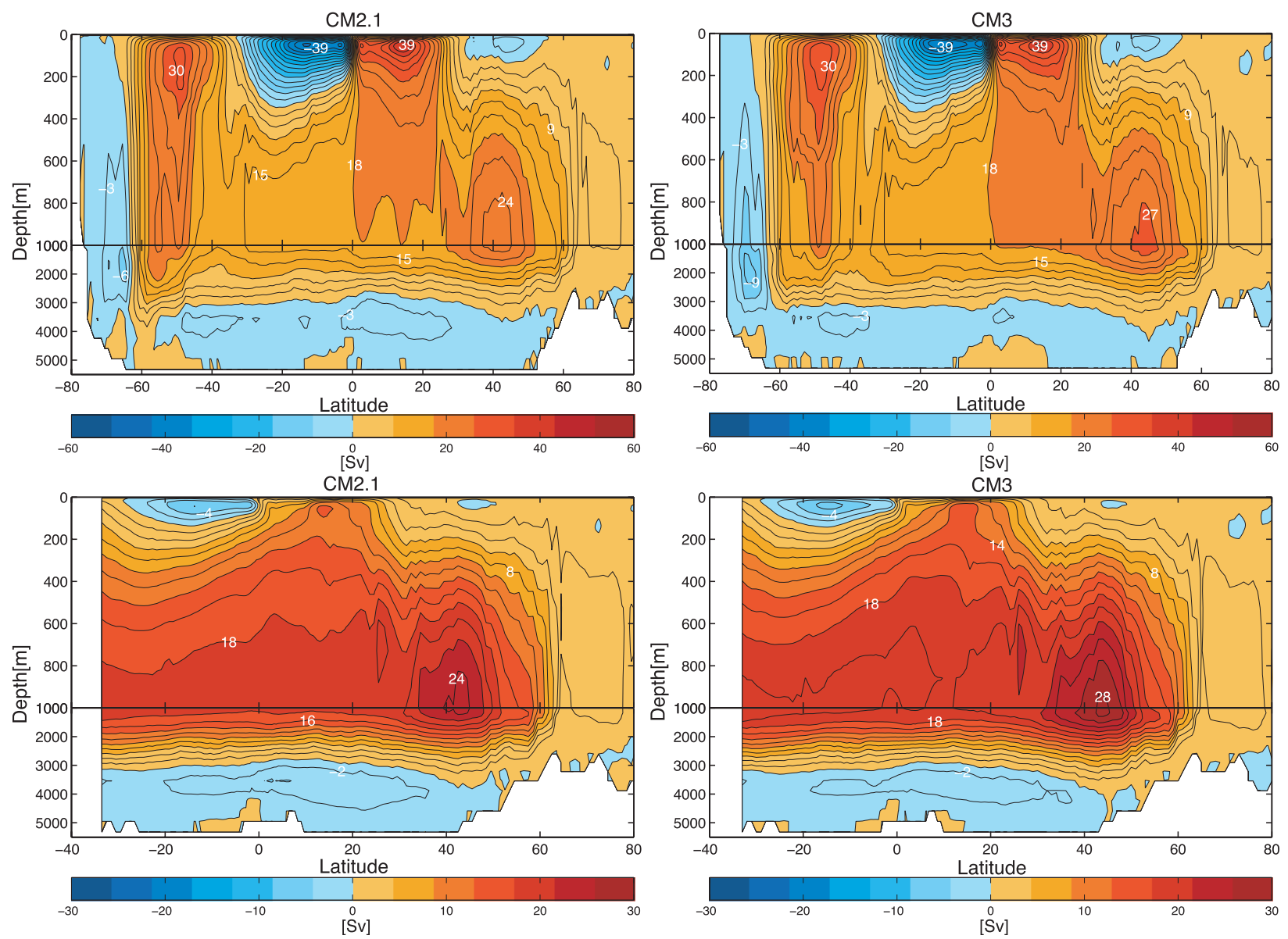

FIG. 16. Time mean (years 1981-2000) and ensemble mean global and Atlantic overturning streamfunctions (Sv) for CM2.1 and CM3 from the historically forced simulations: (top left) CM2.1 global (contour interval $3 \mathrm{~Sv}$ ); (top right) CM3 global (contour interval $3 \mathrm{~Sv}$ ); (bottom left) CM2.1 Atlantic (contour interval $2 \mathrm{~Sv}$ ); and (bottom right) CM3 Atlantic (contour $2 \mathrm{~Sv}$ ). Transport is included from both the resolved Eulerian velocity field as well as the eddy-driven transport parameterized according to Gent and McWilliams (1990). Note the expanded vertical scale for the upper $1000 \mathrm{~m}$ and the different color scale for the Atlantic and global overturnings.

$30^{\circ} \mathrm{S}$ to those of Talley (2008) (Fig. 17). The comparison is made with respect to neutral density surfaces upon which water masses flow easily, requiring no work by buoyancy forcing (McDougall 1987; Jackett and McDougall 1997). Figure 17 provides an inferred estimate of the dianeutral transformation occurring south of $30^{\circ} \mathrm{S}$ and summarizes the fidelity of the simulated water masses in each basin relative to the observational estimate.

Russell et al. (2006) illustrated the ability for CM2.1 to adequately simulate the Talley (2003) observational estimates of meridional volume transport across $32^{\circ} \mathrm{S}$ in the Atlantic Ocean. This ability is evident for both CM2.1 and CM3, as illustrated in Fig. 17, though the bottom water export is very weak compared to Talley (2008). Figure 17 indicates that the level of agreement between the models and observational estimate is considerably poorer in the Indian and Pacific basins. The models have a weak deep counterclockwise overturning cell in the
Indian and Pacific basins, also reflected in the global overturning circulation in Fig. 16, where the strength of the deep water cell north of $50^{\circ} \mathrm{S}$ is less than $5 \mathrm{~Sv}$ between a depth of 3 and $5 \mathrm{~km}$. By comparison, observational studies estimate a zonal average overturning transport of 14-20 Sv for this deep, counterclockwise cell (Orsi et al. 2002; Talley 2003; Lumpkin and Speer 2007). We also find that the warmer bias in the abyssal CM3 (Fig. 14) influences the density at which deep water is transported in the Atlantic basin: in CM3, the southward transport of NADW is concentrated in the 27.5$28.0 \mathrm{~kg} \mathrm{~m}^{-3}$ density range, whereas the same transport is share over the $27.5-28.0$ and $28.0-28.1 \mathrm{~kg} \mathrm{~m}^{-3}$ density ranges in CM2.1.

CM2.1 and CM3 have similar Indonesian Throughflow (ITF) transports (see Table 1), and the basin total Ekman transports are generally in good agreement with observations, except where they are slightly higher in the 

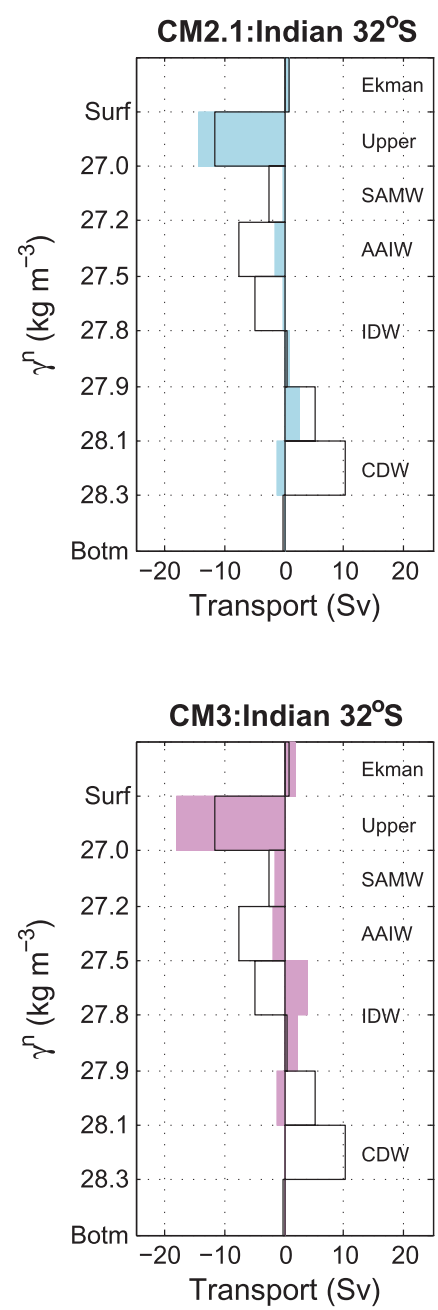
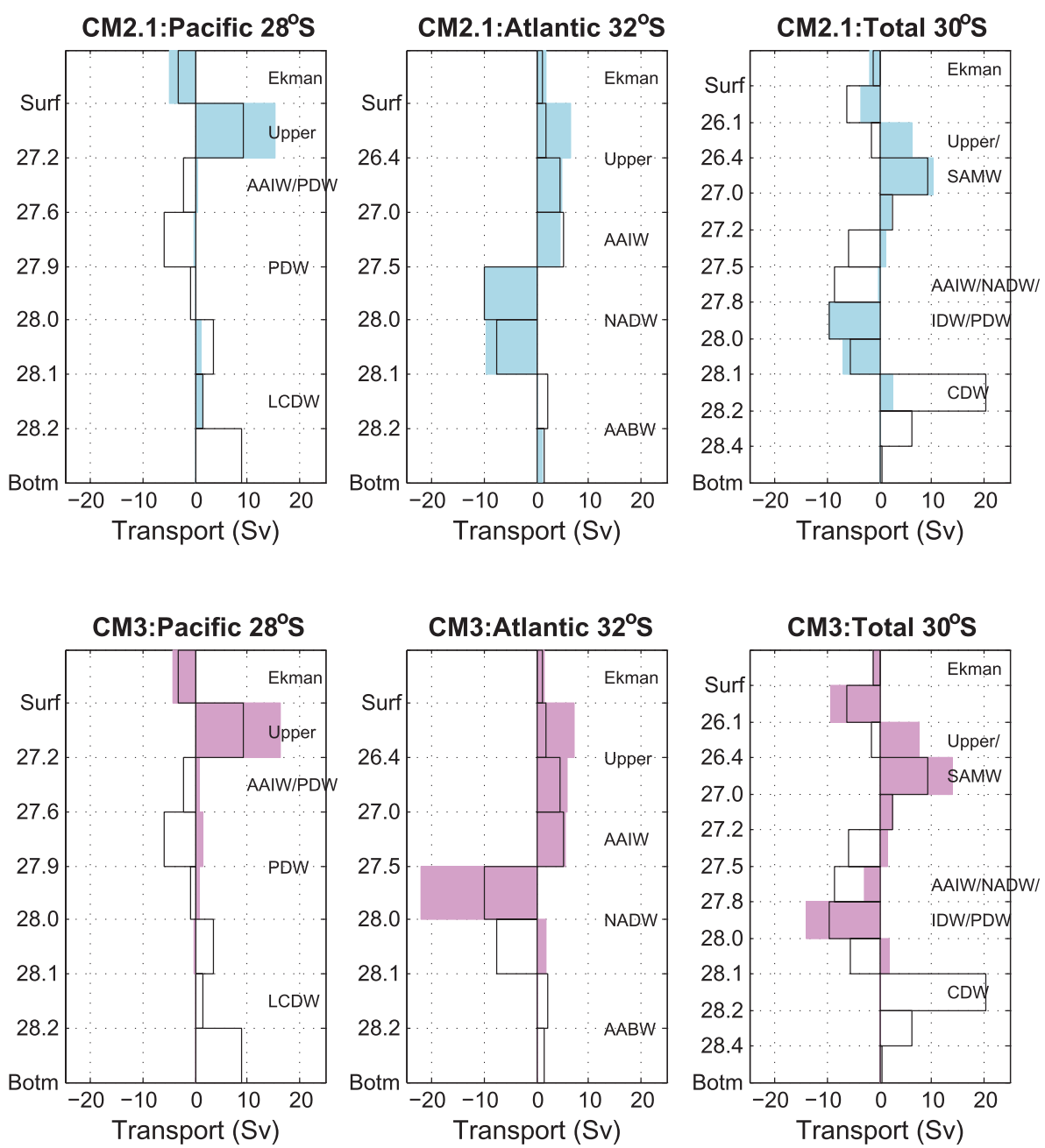

FIG. 17. Meridional volume transports (Sv) on neutral density surfaces $\left[\gamma^{n}\left(\mathrm{~kg} \mathrm{~m}^{-3}\right)\right.$ with respect to $\left.1000 \mathrm{~kg} \mathrm{~m}{ }^{-3}\right]$ across $32^{\circ} \mathrm{S}(\mathrm{Indian}$ and Atlantic Oceans), $28^{\circ} \mathrm{S}$ (Pacific Ocean), and 30 ${ }^{\circ}$ (zonal total). Ensemble means from years 1981-2000 for the coupled models CM2.1 (blue) and CM3 (purple) are compared with observational estimates from Talley (2008) (white bars). Positive (negative) transports indicate northward (southward)flow. (right) Corresponding water masses from Talley (2008) are listed to the right of each plot as Upper Thermocline Waters (Upper), SubAntarctic Mode Water (SAMW), Antarctic Intermediate Water (AAIW), Indian Deep Water (IDW), Circumpolar Deep Water (CDW), Lower Circumpolar Deep Water (LCDW), Pacific Deep Water (PDW), North Atlantic Deep Water (NADW), and Antarctic Bottom Water (AABW). Note that the density bins differ in each basin; densities are between the ocean surface (Surf) and ocean bottom (Botm). The Ekman transport is subtracted from the Upper layer.

Pacific sector. Talley (2008) assumes a 10 Sv ITF transport and uses the National Centers for Environmental Prediction reanalysis wind stress estimates (Kalnay et al. 1996) to calculate the Ekman transport. In both CM2.1 and CM3, the upper layer in the Pacific transports approximately $5 \mathrm{~Sv}$ more than estimated from observations. Talley (2008) suggests that the transport through the ITF originates from surface, intermediate, and deep layers. However, in CM2.1 and CM3, there is little northward flow from the intermediate and deep water masses, hence the upper-layer transport is higher in order to feed a similar ITF transport.

\section{Concluding comments}

We have presented basic simulation features of the ocean and sea ice components within a new coupled climate model, CM3, developed at the NOAA Geophysical Fluid Dynamics Laboratory. Selected model diagnostics and metrics were compared to observations and to the earlier simulation from CM2.1.

CM3 represents an evolutionary step beyond CM2.1 with emphasis on improving formulational aspects and capabilities of the atmosphere and land components. 
Consequently, as detailed in the appendix, the ocean and sea ice components of CM3 remained largely unchanged relative to CM2.1. We thus should expect many of the ocean simulation features in the two climate models to remain similar, as indeed they are, with important exceptions noted below. We believe that it is not possible to generally assume that any particular ocean feature in a climate model will remain robust across two fundamentally distinct atmospheric models. Exposing where the models agree and differ assists in the quest to understand the robustness of climate model simulations. Such efforts, in turn, help to reduce the uncertainty in projections for future climate change.

As a climate model, CM3 is on par oceanographically with CM2.1, with certain features improved and others remaining largely unchanged. We are particularly pleased with improvements in the high northern latitude sea ice thickness (Fig. 11), which will enhance CM3's utility for North Pacific and Arctic sea ice studies (e.g., Holland et al. 2008). Such bias reductions relate to the use of more physically appropriate sea ice albedos in CM3 than used in CM2.1 (see Table A1 in the appendix), improved Arctic sea level pressure patterns (Fig. 12 and Donner et al. 2011), and increases in shortwave heating in the North Pacific (Fig. 3). Furthermore, a reduced warm SST bias off the coast of South America (Fig. 2) is associated with enhanced wind stresses leading to more coastally concentrated upwelling (Fig. 6). Such features may be of use for downscaling studies of relevance for fisheries (Stock et al. 2010). The sizable reductions in the Southern Ocean shortwave biases (Fig. 3) should assist in studies of the Southern Ocean, though we note that the Southern Ocean warm bias is still sufficient to keep the sea ice cover far lower than observational estimates.

An attempt was made to attribute the various changes seen between CM3 and CM2.1, especially with respect to SST. Unambiguously determining such attribution is complex and well beyond the scope of this paper. Nonetheless, through analysis of the direct correlations discussed in relation to Fig. 4, we hypothesize that the SST changes in latitudes equatorward of roughly $40^{\circ}$ can largely be predicted by analysis of the atmospheric fluxes at the ocean surface seen in the AMIP simulations with AM2 and AM3. In contrast, higher latitudes in the coupled model responded in manners quite unexpected from the AMIP simulations, consistent with these regions being dominated by oceanic fluxes and sea ice effects.

Different model initialization procedures (i.e., different spinup time) and different rates of heat absorption by the ocean models handicapped our ability to provide a clean comparison between the historical simulations with CM2.1 and CM3. Such issues with model drift are present with any climate model comparison using realistic forcing in which climate drift, mostly occurring in the ocean interior over multiple centuries, can lead to sizable differences in the simulations. By exposing such differences within the context of two climate models with the same ocean component, we add motivation to understand the mechanisms of this drift, a goal that is both central and urgent for climate modeling. The accuracy of observed air-sea fluxes, which are on the order of tens of watts per square meter (Large and Yeager 2009), is insufficient to constrain the simulated fluxes to the degree necessary to identify sources of climate drift. Instead, the problem of climate drift must be addressed with extensive model sensitivity experiments. It is critical to make progress on reducing climate model drift, as doing so will greatly assist in the goal of developing realistic and accurate climate models suitable for both decadal-tocentennial climate projections, where changes in boundary conditions are of primary importance, and decadal climate forecasts, where proper initial conditions are essential. This represents a topic of ongoing research.

When considering the development of a new climate model, improved understanding and refined numerical methods motivate modifications to the model components. Consequently, maintaining a fixed ocean model component, as for $\mathrm{CM} 3$, is the exception rather than the norm. One area in need of improvement with the CM2.1/CM3 ocean component concerns implementation of the Gent and McWilliams (1990) and Gent et al. (1995) mesoscale eddy parameterization. As suggested by the modeling study of Farneti et al. (2010), the CM2.1 implementation handicaps the parameterization's ability to respond to wind stress changes in the Southern Ocean in a manner suggested by the observational study of Böning et al. (2008). More generally, these results emphasize that development should be guided both by the ability of models to match the observed mean climate state and by their ability to emulate observed sensitivities to changes in climate forcing.

Acknowledgments. We thank the entire staff of GFDL, whose focused efforts over recent years have led to the development of the CM3 coupled climate model. We particularly thank V. Ramaswamy, GFDL's director, for his encouragement and support. We also thank Tom Delworth, Peter Gent, Tony Rosati, Ron Stouffer, and two anonymous reviewers for comments that helped to improve the paper.

\section{APPENDIX}

\section{Ocean and Sea Ice Model Formulation}

The purpose of this appendix is to summarize the formulation of physical parameterizations and numerical 
methods for both the sea ice model and the ocean model. As discussed in Donner et al. (2011), the key goal of the $\mathrm{CM} 3$ project is to enhance the atmospheric representation of physical and chemical processes relative to CM2.1 with focus given to clouds, stratosphere, aerosols, and chemistry. As a strategy to help achieve this goal, we made minimal changes from the CM2.1 ocean and sea ice configurations, which allowed us to focus attention on changes to the atmosphere and land model components. Hence, we may consider the ocean and sea ice components to be effectively identical to that used in CM2.1. The few changes made to these components are described in this appendix.

\section{a. Ocean model}

The ocean model component of CM3 uses version 4p1 of the Modular Ocean Model (MOM4p1) code (Griffies 2009), whereas the ocean component of CM2.1 used the MOM4.0 code (Griffies et al. 2004); the MOM4p1 code is freely available at http://www.gfdl.noaa.gov/fms. The physical parameterizations and grid resolution for the $\mathrm{CM} 3$ ocean are the same as that used in CM2.1, as detailed in Griffies et al. (2005) and Gnanadesikan et al. (2006). The single change made for $\mathrm{CM} 3$ concerns the numerical formulation of the vertical coordinate, discussed below. Tests with the new vertical coordinate in CM2.1 showed trivial changes to the climate simulation. Hence, for purposes of the present paper, the ocean component can be considered the same as that used in CM2.1.

In both $\mathrm{CM} 2.1$ and $\mathrm{CM} 3$, the ocean model resolution is $1^{\circ}$ in latitude and longitude, with refined meridional resolution equatorward of $30^{\circ}$ so that it reaches $1 / 3^{\circ}$ at the equator. There are 50 vertical levels in the ocean with 22 levels of 10-m thickness (with a resting ocean) in the top $220 \mathrm{~m}$. A tripolar horizontal grid with poles over Eurasia, North America, and Antarctica is used to avoid polar filtering over the Arctic (Murray 1996). River flow into the ocean is predicted and is based upon a predetermined river drainage map determined from available global river networks and topographic maps. Any runoff from land cells is routed to an ocean discharge point, with a delay that varies from basin to basin. The water is injected into the ocean evenly over the top four levels (roughly $40 \mathrm{~m}$ ) of ocean. There are six inland seas (Hudson Bay, Black Sea, Mediterranean Sea, Red Sea, Baltic Sea, and the Persian Gulf) that are connected to the World Ocean only via mixing processes at the connecting points between the inland seas and the open ocean (Griffies et al. 2005).

\section{1) NeW Vertical COORDinAte}

The MOM4p1 code generalizes the vertical discretization of its levels. We chose in $\mathrm{CM} 3$ to exploit this added generality by using the $z^{*}$ vertical coordinate of Stacey et al. (1995) and Adcroft and Campin (2004), defined according to

$$
z^{*}=H\left(\frac{z-\eta}{H+\eta}\right) .
$$

In this equation, $z=\eta(x, y, t)$ is the deviation of the ocean free surface from a state of rest at $z=0$, and $z=$ $-H(x, y)$ is the ocean bottom. Whereas a geopotential ocean model places all free surface undulations into the top model grid cell, a $z^{*}$ model distributes the undulations throughout the ocean column. All grid cells thus have a time dependent thickness with $z^{*}$. Surfaces of constant $z^{*}$ differ from geopotential surfaces according to the ratio $\eta / H$, which is generally quite small. Hence, surfaces of constant $z^{*}$ are quasi horizontal, thus minimizing difficulties of accurately computing the horizontal pressure gradient [see Griffies et al. (2000) for a review]. The $z^{*}$ vertical coordinate is analogous to the "eta" coordinate sometimes used for atmospheric models (Black 1994).

We chose $z^{*}$ for CM3 because of its enhanced flexibility when considering two key applications of climate models beyond those considered in this paper. The first application concerns large surface height deviations associated with tides and/or increased loading from sea ice (e.g., a global cooling simulation). The $z^{*}$ model allows for the free surface to fluctuate to values as large as the local ocean depth, $|\eta|<H$, whereas the geopotential model is subject to the more stringent constraint $|\eta|<$ $\Delta z_{1}$, with $\Delta z_{1}$ the thickness of the top grid cell with a resting ocean. The ocean models in CM2.1 and CM3 set a minimum depth to $H \geq 40 \mathrm{~m}$, whereas $\Delta z_{1}=10 \mathrm{~m}$ (note that there is no wetting and drying algorithm in MOM4p1). This flexibility with $z *$ is further exploited if considering even finer vertical grid resolution. The second application where $z^{*}$ is useful concerns increased land ice melt that adds substantially to the sea level, as in the idealized studies of Stouffer et al. (2006b), Kopp et al. (2010), and Yin et al. (2010b). Placing all of the surface expansion into the top model grid cell, as with the free surface geopotential model, greatly coarsens the vertical grid resolution in this important portion of the ocean, whereas the $z^{*}$ model does not suffer from this problem since the expansion is distributed throughout the column.

\section{2) REAL WATER FLUXES}

As in CM2.1, the CM3 ocean model uses a water flux surface boundary condition. Hence, the transport of water across the ocean boundary is associated with a change in ocean volume (as per the Boussinesq approximation). As 
TABLE A1. Albedos used in the sea ice model for CM2.1 and CM3. The transition from dry to wet albedos occurs linearly, starting at $10 \mathrm{~K}$ below freezing for CM2.1 and $1 \mathrm{~K}$ below freezing for CM3. This transition range was much larger (and less realistic) in CM2.1 to counteract biases that rendered too much Northern Hemisphere sea ice in CM2.1, especially in the North Pacific. The albedos in CM2.1 were similarly set low to reduce the excessive ice cover.

\begin{tabular}{lcc}
\hline \hline \multicolumn{1}{c}{ Parameter } & CM2.1 & CM3 \\
\hline Snow albedo (dry/wet) & $0.80 / 0.68$ & $0.85 / 0.73$ \\
Ice albedo (dry/wet) & $0.58 / 0.51$ & $0.68 / 0.61$ \\
Transition $\Delta T(\mathrm{~K})$ & 10 & 1 \\
$\quad$ from dry to wet & & \\
\hline
\end{tabular}

discussed in Huang (1993), Griffies et al. (2001), Griffies et al. (2005), and Yin et al. (2010b), the water flux boundary provides for the following improvements in model formulation and behavior relative to the older virtual salt flux method.

- Salt within the ocean is constant, except for the small amounts exchanged with the sea ice model (which uses a constant salinity of $5 \mathrm{ppt}$ ).

- There are more realistic feedbacks associated with rivers, precipitation, and evaporation.

- The Goldsbrough-Stommel circulation is admitted, as it is driven by hydrological forcing.

- There are barotropic signals and mass redistributions associated with the exchange of water with other climate components. As highlighted by Kopp et al. (2010), the ability to exchange mass with other climate components facilitates studies of how mass redistributions in the climate system impact the earth's gravity field and rotation, both of which are critical for understanding and quantifying sea level change.

Many climate models do not use the water flux boundary condition, even those that employ a free surface in which the introduction of water is algorithmically trivial. Instead, they use the virtual salt flux commonly used in rigid-lid ocean models (see Huang 1993 and Griffies et al. 2001 for discussion and critique). The above-listed reasons in favor of the water flux boundary condition serve as strong motivation to favor it over virtual tracer fluxes.

\section{b. Sea ice model}

The CM3 sea ice model is identical to that used for CM2.1, as documented in Delworth et al. (2006) and Winton (2000), and it uses the same horizontal grid arrangement of the ocean model. Importantly, improvements in regional climate biases, many of which are discussed in section 2, allowed the ice and snow-on-ice albedos to be tuned brighter in CM3 than CM2.1 (see Table A1), which brings them to more realistic settings (Perovich et al. 2002).

\section{REFERENCES}

Adcroft, A., and J.-M. Campin, 2004: Rescaled height coordinates for accurate representation of free-surface flows in ocean circulation models. Ocean Modell., 7, 269-284.

Bitz, C., J. Fyfe, and G. Flato, 2002: Sea ice response to wind forcing from AMIP models. J. Climate, 15, 522-536.

Black, T. L., 1994: The new NMC mesoscale eta model: Description and forecast examples. Wea. Forecasting, 9, 265-278.

Böning, C. W., A. Dispert, M. Visbeck, S. Rintoul, and F. Schwarzkopf, 2008: The response of the Antarctic Circumpolar Current to recent climate change. Nat. Geosci., 1, 864-869.

Bourke, R. H., and R. P. Garrett, 1987: Sea ice thickness distribution in the Arctic Ocean. Cold Reg. Sci. Technol., 13, 259-280.

Cavalieri, D., C. Parkinson, and K. Vinnikov, 2003: 30-year satellite record reveals conrasting Arctic and Antarctic decadal variability. Geophys. Res. Lett., 30, 1970, doi:10.1029/ 2003GL018031.

Cunningham, S., S. Alderson, B. King, and M. Brandon, 2003: Transport and variability of the Antarctic Circumpolar Current in Drake Passage. J. Geophys. Res., 108, 8084, doi:10.1029/ 2001JC001147.

Delworth, T. L., and Coauthors, 2006: GFDL's CM2 global coupled climate models. Part I: Formulation and simulation characteristics. J. Climate, 19, 643-674.

DiMarco, S. F., and Coauthors, 2002: Volume transport and property distributions of the Mozambique Channel. Deep-Sea Res. II, 49, 1481-1511.

Donner, L. J., and Coauthors, 2011: The dynamical core, physical parameterizations, and basic simulation characteristics of the atmospheric component of the GFDL global coupled model CM3. J. Climate, 24, 3484-3519.

Farneti, R., T. Delworth, A. Rosati, S. Griffies, and F. Zeng, 2010: The role of mesoscale eddies in the rectification of the Southern Ocean response to climate change. J. Phys. Oceanogr., 40, 1539-1557.

Fetterer, F., K. Knowles, W. Meier, and M. Savoie, 2009: Sea ice index. National Snow and Ice Data Center, Boulder, CO, digital media. [Available online at http://nsidc.org/data/seaice_index/.]

Fissel, D., J. Birch, H. Melling, and R. Lake, 1998: Non-tidal flows in the Northwest Passage. Canadian Tech. Rep. of Hydrography and Ocean Sciences, Institute of Ocean Sciences, 142 pp.

Ganachaud, A., 2003: Large-scale mass transports, water mass formation, and diffusivities estimated from World Ocean Circulation Experiment (WOCE) hydrographic data. J. Geophys. Res., 108, 3213, doi:10.1029/2002JC001565.

_ transports during the World Ocean Circulation Experiment. J. Climate, 16, 696-705.

Gates, W., 1993: AMIP: The Atmosphere Model Intercomparison Project. Bull. Amer. Meteor. Soc., 73, 1962-1970.

Gent, P. R., and J. C. McWilliams, 1990: Isopycnal mixing in ocean circulation models. J. Phys. Oceanogr., 20, 150-155.

- J. Willebrand, T. J. McDougall, and J. C. McWilliams, 1995: Parameterizing eddy-induced tracer transports in ocean circulation models. J. Phys. Oceanogr., 25, 463-474.

GFDL GAMDT, 2004: The new GFDL global atmosphere and land model AM2/LM2: Evaluation with prescribed SST simulations. J. Climate, 17, 4641-4673.

Gnanadesikan, A., and Coauthors, 2006: GFDL's CM2 global coupled climate models. Part II: The baseline ocean simulation. J. Climate, 19, 675-697. 
_ S. Griffies, and B. Samuels, 2007: Effects in a climate model of slope tapering in neutral physics schemes. Ocean Modell., 17, 1-16.

Gordon, A., R. Susanto, A. Ffield, B. Huber, W. Pranowo, and S. Wirasantosa, 2008: Makassar Strait throughflow, 2004 to 2006. Geophys Res. Lett., 35, L24605, doi:10.1029/2008GL036372.

Greatbatch, R. J., 1994: A note on the representation of steric sea level in models that conserve volume rather than mass. J. Geophys. Res., 99, 12 767-12 771.

Griffies, S. M., 2009: Elements of MOM4p1: GFDL Ocean Group Tech. Rep. 6. NOAA/Geophysical Fluid Dynamics Laboratory, $444 \mathrm{pp}$.

- , and Coauthors, 2000: Developments in ocean climate modelling. Ocean Modell., 2, 123-192.

_-, R. Pacanowski, M. Schmidt, and V. Balaji, 2001: Tracer conservation with an explicit free surface method for $z$-coordinate ocean models. Mon. Wea. Rev., 129, 1081-1098.

— M. J. Harrison, R. C. Pacanowski, and A. Rosati, 2004: A Technical Guide to MOM4. NOAA/Geophysical Fluid Dynamics Laboratory, $337 \mathrm{pp}$.

— , and Coauthors, 2005: Formulation of an ocean model for global climate simulations. Ocean Sci., 1, 45-79.

— WCRP CMIP5 simulations. ICPO Publication Series 137, WCRP Informal Rep. 3/2009, 55 pp.

— , and Coauthors, 2009b: Coordinated Ocean-Ice Reference Experiments (COREs). Ocean Modell., 26, 1-46, doi:10.1016/ j.ocemod.2008.08.007.

Holland, M., M. Serreze, and J. Stroeve, 2008: The sea ice mass budget of the Arctic and its future change as simulated by coupled climate models. Climate Dyn., 34, 185-200, doi:10.1007/ s00382-008-0493-4.

Huang, R. X., 1993: Real freshwater flux as a natural boundary condition for the salinity balance and thermohaline circulation forced by evaporation and precipitation. J. Phys. Oceanogr., 23, 2428-2446.

Hurrell, J., J. Hack, D. Shea, J. Caron, and J. Rosinski, 2008: A new sea surface temperature and sea ice boundary data set for the Community Atmosphere Model. J. Climate, 21, 51455153.

Ingvaldsen, R., L. Asplin, and H. Loeng, 2004: The seasonal cycle in the Atlantic transport to the Barents Sea during 1997-2001. Cont. Shelf Res., 24, 1015-1032.

Jackett, D. R., and T. J. McDougall, 1997: A neutral density variable for the world's oceans. J. Phys. Oceanogr., 27, 237-263.

Kalnay, E., and Coauthors, 1996: The NCEP/NCAR 40-Year Reanalysis Project. Bull. Amer. Meteor. Soc., 77, 437-471.

Kopp, G., G. Lawrence, and G. Rottman, 2005: The total irradiance monitor (TIM): Science results. Sol. Phys., 230, 129-139.

Kopp, R. E., J. X. Mitrovica, S. M. Griffies, J. Yin, C. C. Hay, and R. J. Stouffer, 2010: The impact of Greenland melt on regional sea level: A preliminary comparison of dynamic and static equilibrium effects. Climatic Change Lett., 103, 619-625, doi:10.1007/s10584-010-9935-1.

Kwok, R., and D. A. Rothrock, 2009: Decline in Arctic sea ice thickness from submarine and ICESat records: 1958-2008. Geophys. Res. Lett., 36, L15501, doi:10.1029/2009GL039035.

Large, W. G., and S. Yeager, 2009: The global climatology of an interannually varying air-sea flux data set. Climate Dyn., 33, 341-364, doi:10.1007/s00382-008-0441-3.

Lee, H.-C., A. Rosati, and M. Spelman, 2006: Barotropic tidal mixing effects in a coupled climate model: Oceanic conditions in the northern atlantic. Ocean Modell., 3-4, 464-477.
Loeb, N., B. Wielicki, D. Doelling, G. Smith, D. Keyes, S. Kato, N. Manalo-Smith, and T. Wong, 2009: Toward optimal closure of the earth's top-of-atmosphere radiation budget. J. Climate, 22, 748-766.

Lucarini, V., and F. Ragone, 2011: Energetics of climate models: Net energy balance and meridional enthalpy transport. Rev. Geophys., 49, RG1001, doi:10.1029/2009RG000323.

Lukas, R., and E. Firing, 1984: The geostrophic balance of the Pacific equatorial undercurrent. Deep-Sea Res., 31, 61-66.

Lumpkin, R., and K. Speer, 2003: Large-scale vertical and horizontal circulation in the North Atlantic Ocean. J. Phys. Oceanogr., 33, 1902-1920.

— and - 2007: Global ocean meridional overturning. J. Phys. Oceanogr., 37, 2550-2562.

Lyman, J., and Coauthors, 2010: Robust warming of the global upper ocean. Nature, 465, 334-337.

Maximenko, N., and P. Niiler, 2005: Hybrid decade-mean global sea level with mesoscale resolution. Recent Advances in $M a$ rine Science and Technology 2004, N. Saxena, Ed., PACON International, 55-59.

McDougall, T. J., 1987: Neutral surfaces. J. Phys. Oceanogr., 17, 1950-1967.

Meehl, G., C. Covey, T. Delworth, M. Latif, B. McAvaney, J. Mitchell, R. Stouffer, and K. Taylor, 2007: The WCRP CMIP3 multimodel dataset: A new era in climate change research. Bull. Amer. Meteor. Soc., 88, 1383-1394.

Melling, H., 2000: Exchanges of freshwater through the shallow straits of the North American Arctic. The Freshwater Budget of the Arctic Ocean, Kluwer Academic Publishers, 472-523.

Murray, R. J., 1996: Explicit generation of orthogonal grids for ocean models. J. Comput. Phys., 126, 251-273.

Olsen, S., B. Hansen, D. Quadfasel, and S. Osterhus, 2008: Observed and modelled stability of overflow across the GreenlandScotland ridge. Nature, 455, 302, doi:10.1038/nature07302.

Orsi, A. H., W. M. Smethie Jr., and J. L. Bullister, 2002: On the total input of Antarctic waters to the deep ocean: A preliminary estimate from chlorofluorocarbon measurements. J. Geophys. Res., 107, 3122, doi:10.1029/2001JC000976.

Osterhus, S., W. Turrell, S. Jonsson, and B. Hansen, 2005: Measured volume, heat, and salt fluxes from the Atlantic to the Arctic Mediterranean. Geophys. Res. Lett., 32, 188, doi:10.1029/ 2004GL022188.

Perovich, D., T. C. Grenfell, B. Light, and P. V. Hobbs, 2002: Seasonal evolution of the albedo of multiyear Arctic sea ice. J. Geophys. Res., 107, 8044, doi:10.1029/2000JC000438.

Randall, D., and Coauthors, 2007: Climate models and their evaluation. Climate Change 2007: The Physical Science Basis, S. Solomon et al., Eds., Cambridge University Press, 589-662.

Reynolds, R. W., N. Rayner, T. M. Smith, D. Stokes, and W. Wang, 2002: An improved in situ and satellite SST analysis for climate. J. Climate, 15, 1609-1625.

Roach, A., K. Aagard, C. Pease, S. Salo, T. Weingartner, V. Pavlov, and M. Kulakov, 1995: Direct measurements of transport and water properties through Bering Strait. J. Geophys. Res., 100, 18 443-18 457.

Russell, J., R. Stouffer, and K. Dixon, 2006: Intercomparison of the Southern Ocean circulations in the IPCC coupled model control simulations. J. Climate, 19, 4560-4575.

Sadler, H., 1976: Water, heat and salt transports through Nares Strait, Ellesmere Island. J. Fish. Res. Board Canada, 33, 2286-2295.

Schauer, U., E. Fahrbach, S. Osterhus, and G. Rohardt, 2004: Arctic warming through the Fram Strait: Oceanic heat transport from 
3 years of measurements. J. Geophys. Res., 109, C06026, doi:10.1029/2003JC001823.

Serreze, M., M. Holland, and J. Stroeve, 2007: Perspectives on the Arctic sinking sea-ice cover. Science, 315, 1533-1536, doi:10.1126/science.1139426.

Sloyan, B., and I. Kamenkovich, 2007: Simulation of Subantarctic Mode and Antarctic Intermediate Waters in climate models. J. Climate, 20, 5061-5080.

— , G. Johnson, and W. Kessler, 2003: The Pacific cold tongue: A pathway for interhemispheric exchange. J. Phys. Oceanogr., 33, 1027-1043.

Stacey, M. W., S. Pond, and Z. P. Nowak, 1995: A numerical model of the circulation in Knight Inlet, British Columbia, Canada. J. Phys. Oceanogr., 25, 1037-1062.

Steele, M., R. Morfley, and W. Ermold, 2001: PHC: A global ocean hydrography with a high-quality Arctic Ocean. J. Climate, 14, 2079-2087.

Stock, C. A., and Coauthors, 2010: On the use of IPCC-class models to assess the impact of climate on living marine resources. Prog. Oceanogr., 88, 1-27, doi:10.1016/j.pocean.2010.09.001.

Stouffer, R. J., 2004: Time scales of climate response. J. Climate, 17, 209-217.

— A. Weaver, and M. Eby, 2004: A method for obtaining pretwentieth century initial conditions for use in climate change studies. Climate Dyn., 23, 327-339.

, and Coauthors, 2006a: GFDL's CM2 global coupled climate models. Part IV: Idealized climate response. J. Climate, 19, $723-740$
- , and Coauthors, 2006b: Investigating the causes of the response of the thermohaline circulation to past and future climate changes. J. Climate, 19, 1365-1387.

Talley, L., 2003: Shallow, intermediate, and deep overturning components of the global heat budget. J. Phys. Oceanogr., 33, 530-560.

- 2008: Freshwater transport estimates and the global overturning circulation: Shallow, deep and throughflow components. Prog. Oceanogr., 78, 257-303.

Tian, J., Q. Yang, X. Liang, L. Xie, D. Hu, F. Wang, and T. Qu, 2006: Observation of the Luzon Strait transport. Geophys. Res. Lett., 33, L19607, doi:10.1029/2006GL026272.

Trenberth, K., and J. Caron, 2001: Estimates of meridional atmosphere and ocean heat transports. J. Climate, 14, 3433-3443.

Uppala, S., and Coauthors, 2005: The ERA-40 Re-Analysis. Quart. J. Roy. Meteor. Soc., 131, 2961-3012.

Winton, M., 2000: A reformulated three-layer sea ice model. J. Atmos. Oceanic Technol., 17, 525-531.

Wittenberg, A., A. Rosati, G. Lau, and J. Ploshay, 2006: GFDL's CM2 global coupled climate models. Part III: Tropical Pacific climate and ENSO. J. Climate, 19, 698-722.

Yin, J., S. Griffies, and R. J. Stouffer, 2010a: Spatial variability of sea-level rise in twenty-first century projections. J. Climate, 23, 4585-4607.

—- R. Stouffer, M. Spelman, and S. Griffies, 2010b: Evaluating the uncertainty induced by the virtual salt flux assumption in climate simulations and future projections. J. Climate, $\mathbf{2 3}$, 80-96. 